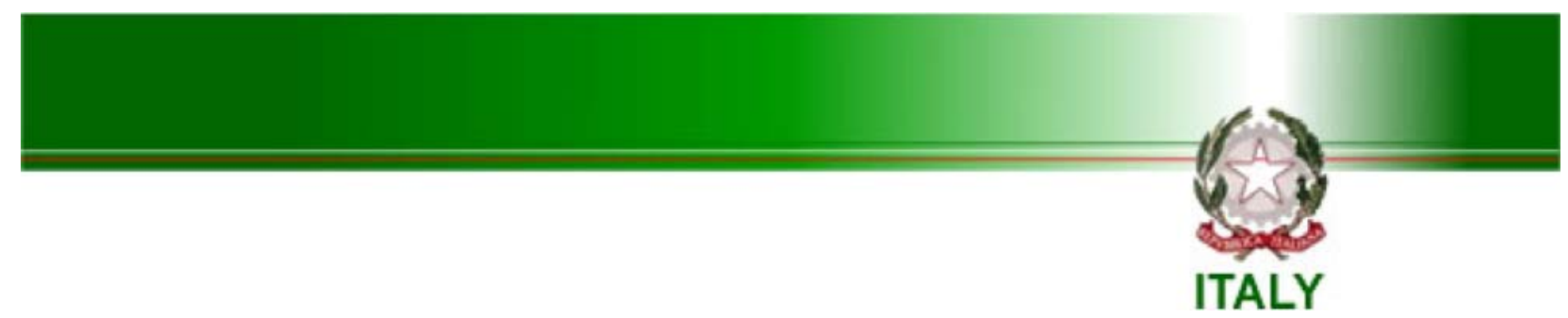

Convention on

Nuclear Safety

Sixth Italian National Report 



\title{
Convention on
}

\author{
Nuclear Safety
}

\section{Sixth Italian National Report}

This National Report has been prepared on behalf of the Italian Government by the Institute for Environmental Protection and Research (ISPRA) 



\section{TABLE OF CONTENTS}

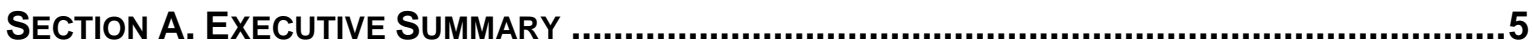

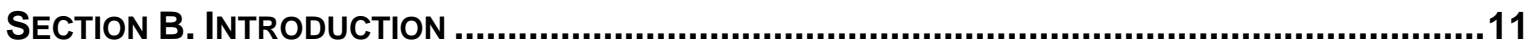

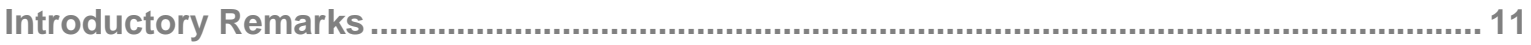

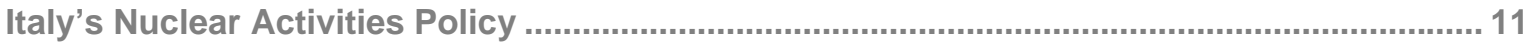

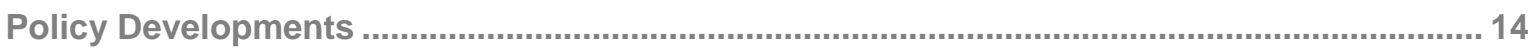

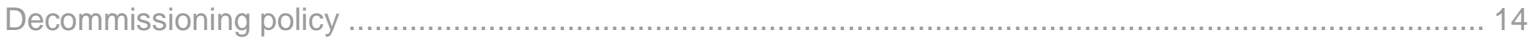

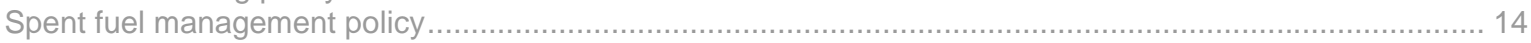

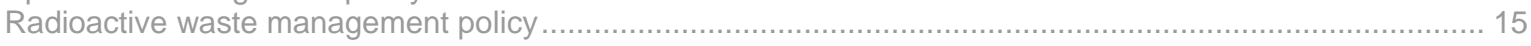

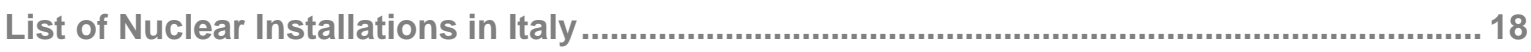

Italian Participation in International Activities to Enhance Nuclear Safety ............................ 18

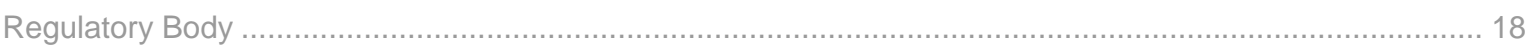

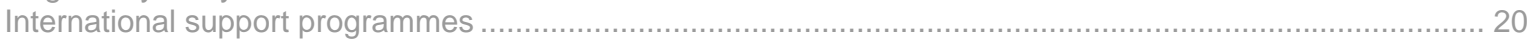

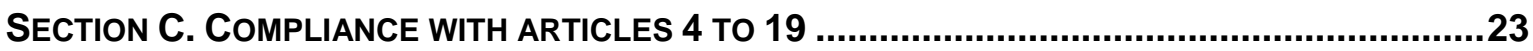

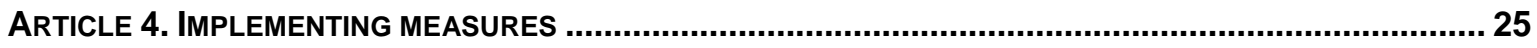

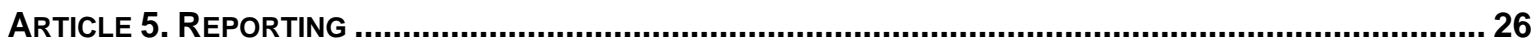

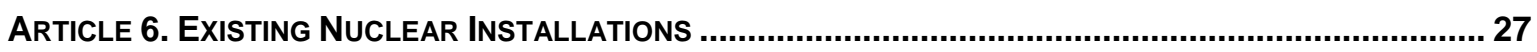

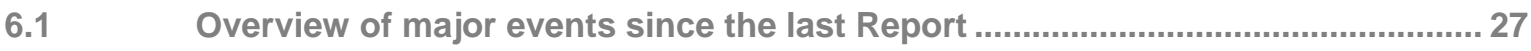

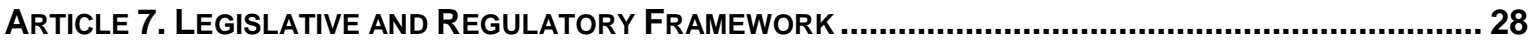

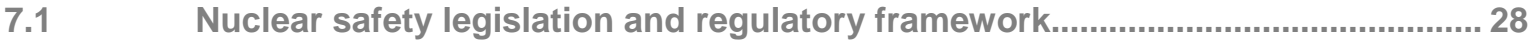

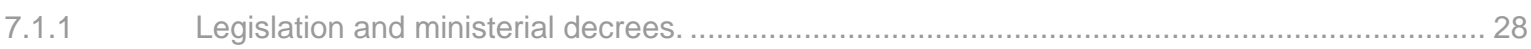

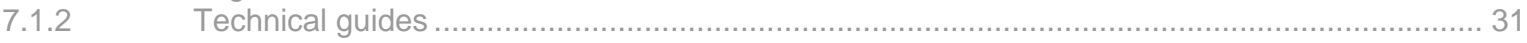

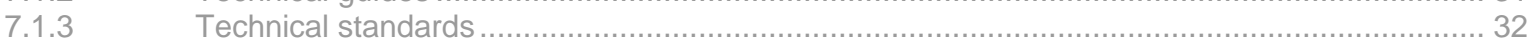

7.2 National safety requirements and regulations for radiation safety ..................... 32

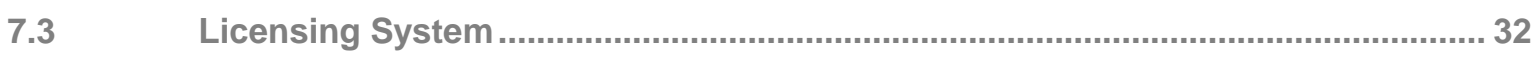

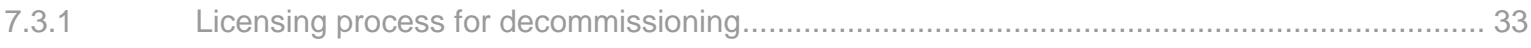

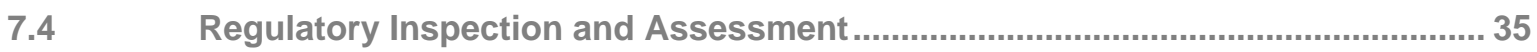

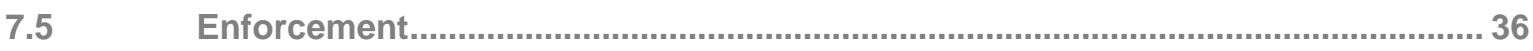

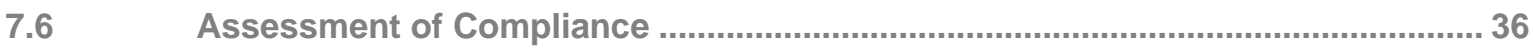

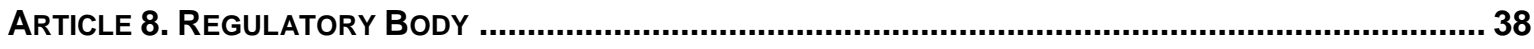

8.1 Authorities responsible for the application of the legislative framework .......... 38

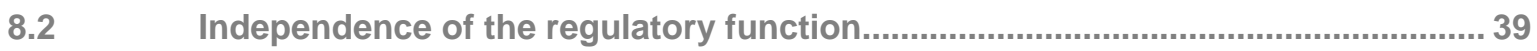

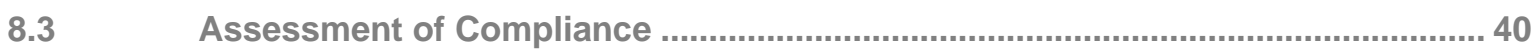

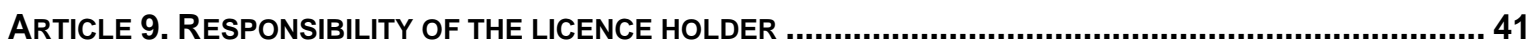

9.1 Responsibility of the licence holder......................................... 41

9.2 Ensuring that the license holder meets its responsibility for safety ...................41

9.3 Assessment of compliance .......................................................................... 42 


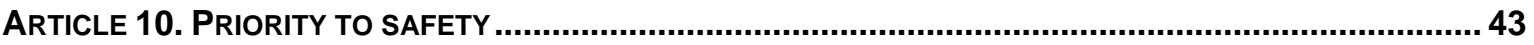

10.1 Assessment of compliance ...................................................... 44

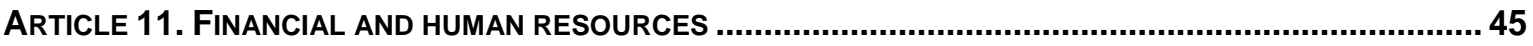

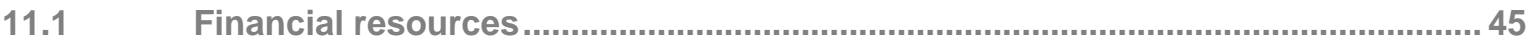

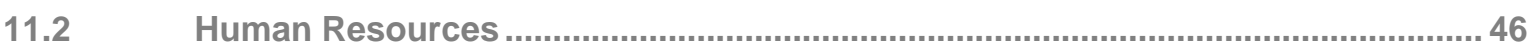

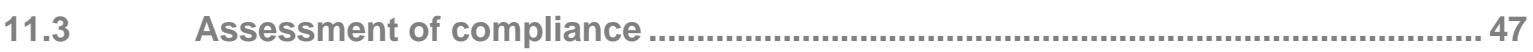

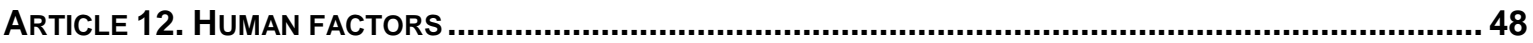

12.1 Methods to prevent, detect and correct human errors................................ 48

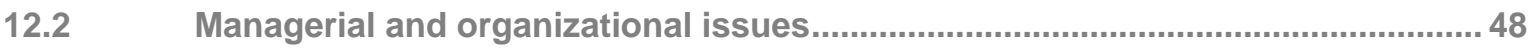

12.3 Safety culture and Safety Management System (SMS) and associated surveillance roles ....................49

12.4 Role of the Regulatory Body and of the Operator regarding Human Performances issues ................................................................................................................... 50

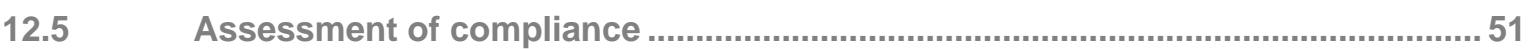

ARTICLE 13. QUALITY ASSURANCE.................................................................................. 53

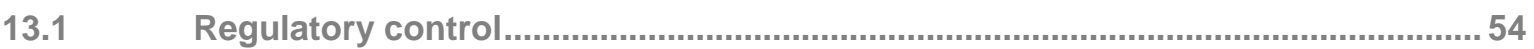

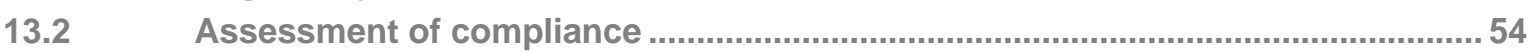

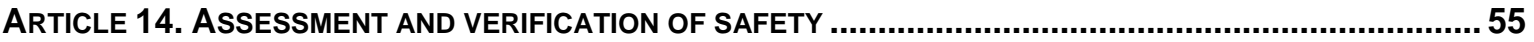

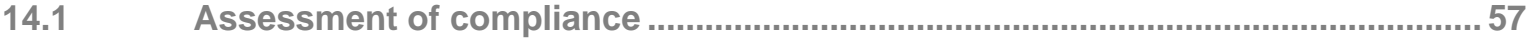

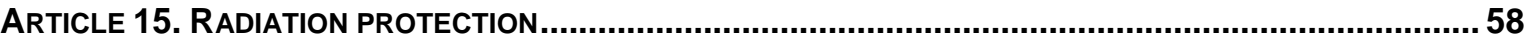

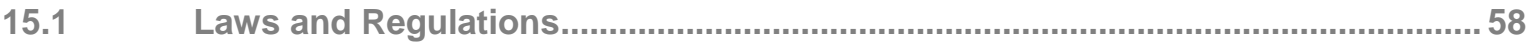

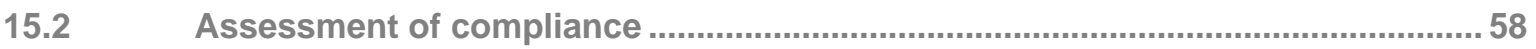

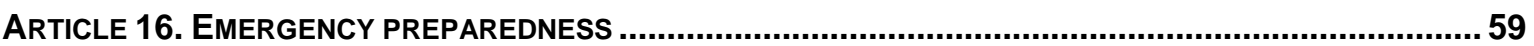

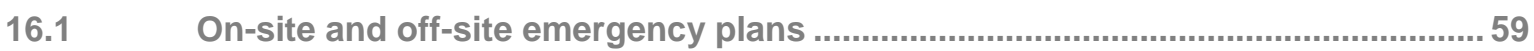

$16.2 \quad$ National Plan against Radiological Emergency ................................................6 60

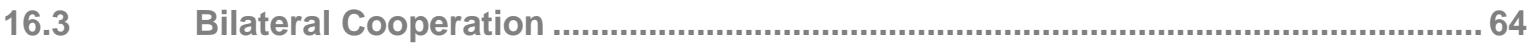

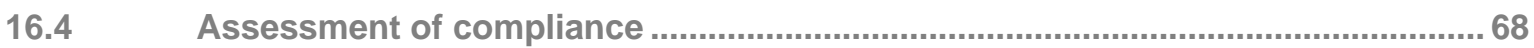

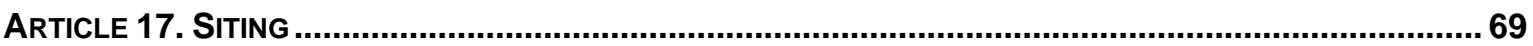

ARTICLE 18. DESIGN AND CONSTRUCTION ................................................................................. 70

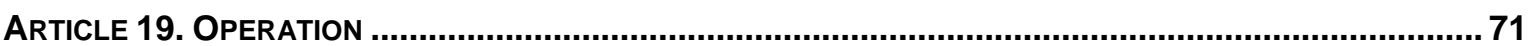

SECTION D. TOPICS OF INTEREST FROM THE $5^{\text {TH }}$ REVIEW MEETING ................................ 73

SECTION E. PlanNEd ACTIVITIES TO IMPROVE SAFETY .............................................. 77

SECTION F. LIST OF ACRONYMS ........................................................................ 83

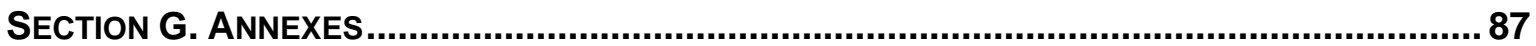

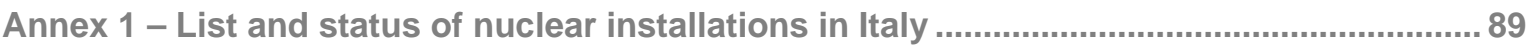

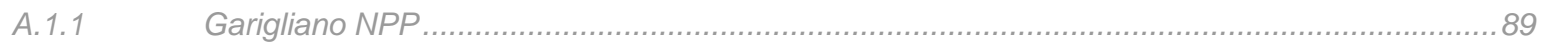

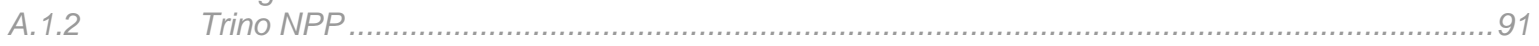

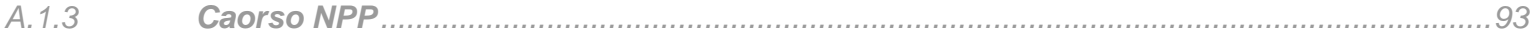

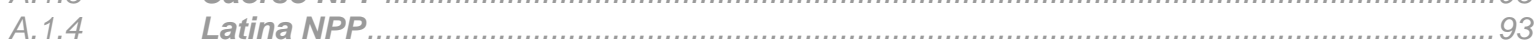


Annex 2 - Background historical information on the past Italian nuclear programme. 97

Annex 3 - List of acts, decrees, regulations, guides and standards.................................... 99

Annex 4 - Additional information on safety and radiation protection rules ....................... 108

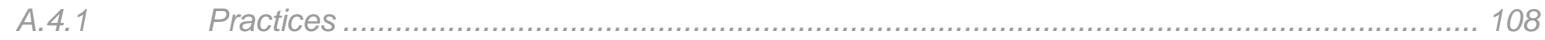

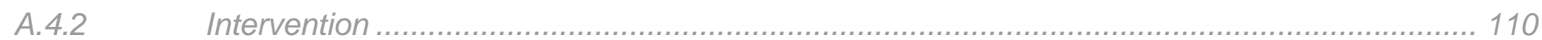

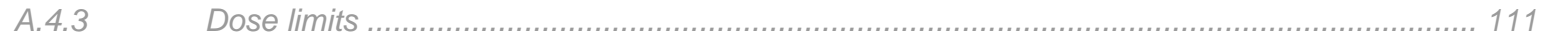

A.4.4 Radiological safety objectives and Authorised Limits............................................... 113

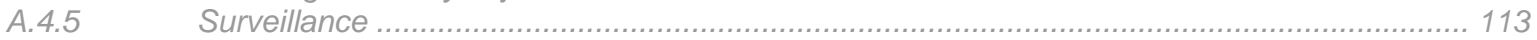

A.4.6 Radiation Protection Inspections and enforcement ................................................ 114

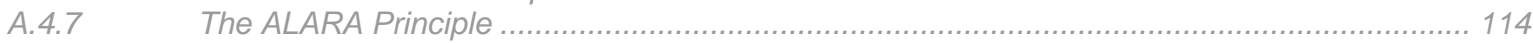

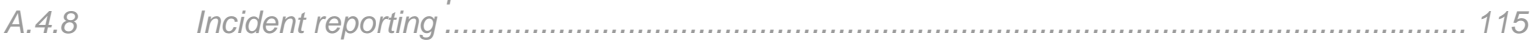

Annex 5 - Structure of the global decommissioning programme .................................... 117 

Section A. Executive Summary 

This National Report, pursuant to Article 5 of the Convention on Nuclear Safety which entered into force on 24 October 1996, describes the official actions that the Government of the Republic of Italy, as a Contracting Party to the Convention since 15 April 1998, has taken in order to fulfil its obligations as specified in Articles 6 through 19 of the Convention.

This Report is the sixth National Report. It represents a revision to the fifth Report submitted by Italy on October 2010 for the fifth Review Meeting of April 2011 and to the Report submitted for the Extraordinary Meeting held in 2012 to address lessons learned from the accident at Fukushima Daiichi NPP. This sixth National Report was prepared in accordance with the "Guidelines Regarding National Reports under the Convention on Nuclear Safety". It contains updated information on matters covered in the previous Reports, as well as in the Report for Extraordinary Meeting in 2012, noting significant changes occurred in national laws, regulations and practices. This Report also addresses topics of interest identified in the previous Report during the fifth Review Meeting and provides information on technical issues related to the Fukushima accident and to the implementation of the IAEA Action Plan on Nuclear Safety as applicable to the state of the nuclear installations in Italy.

Nuclear installations covered in this National Report are land based civil nuclear power plants under the jurisdiction of the Republic of Italy complying with the definition given under the Article 2i. It has to be considered that such compliance is quite formal; in fact, all the four Italian plants (Garigliano, Latina, Trino and Caorso NPPs) were definitively shut down about 25 years ago and all the fuel elements have been removed permanently from the reactors' core of each plant.

In addition, spent fuel is currently present only at the Trino NPP and at Avogadro AFR facility in the amount of about 30 tons. Its transfer abroad for reprocessing is expected to be completed by 2015 according to the institutional and industrial agreements described in the $5^{\text {th }}$ Report. Its safe management continues to be performed according to existing licence conditions and technical specifications.

Since the time of the fifth Report a major event in Italy regards the new nuclear power program decided by the Italian Government in 2009. In fact, after the Fukushima Daiichi NPP accident and on the bases of the results of a national referendum held in June 2011, such a program was abandoned and the established nuclear legislative regime was correspondingly amended.

Among major developments since the fifth Report, it is reported that authorisations to the overall decommissioning plans - established by the nuclear Act - have been granted to two plants (i.e. Garigliano and Trino). In the light of the above referred authorizations, only Caorso and Latina plants still comply with the definition given under the Article $2 \mathrm{i}$ and are therefore dealt with in the Report as nuclear installations. It is to be noted that the authorization of the overall decommissioning plan of the Caorso NPP is expected to be granted by the end of the year and that of the Latina NPP is expected to follow in 2014. 
Some decommissioning related activities, not involving parts or components of nuclear islands, continue to progress on the basis of authorisations granted according to specific provisions of the nuclear Act.

It has to be noted how, in the light of the Italian plants' state, all the safety matter dealt with in this Report falls in the scope of the Joint Convention.

As a consequence of the referred new nuclear power programme abandonment, it is reported how the new Nuclear Safety Agency established by the Law 99/2009 and never become effective was abolished on December, 2011 and its functions and duties were maintained to ISPRA that is continuing its work as Nuclear Regulatory Authority, waiting for a definitive asset of the national regulatory organization. It is expected that such a reorganization will represent a proper context for Government's actions to overcome the experienced human resources shortage in medium and long term at the Regulator as highlighted in the fifth Review Meeting. From the Implementer side, a programme of recruitment of new personnel is in progress.

As discussed in the fifth Report on the difficulties encountered by the Government in the process of establishing a centralized radioactive waste storage and disposal facility, it is reported that in 2012 ISPRA has been charged with the task to develop technical siting criteria for the identification of potential areas where to realize a LLW near surface disposal facility and an Interim storage for ILW and HLW.

A first draft of a Technical Guide on Siting Criteria for Low Level Near Surface Disposal Facilities has been prepared by ISPRA and a process of international review has been conducted. In particular, a peer review of this technical Guide has been requested to the IAEA and completed in September 2013. Technical exchange on the matter also took place with Nuclear Safety Authorities of France, Switzerland, Belgium and Slovenia. This technical guide will be issued according to a procedure established in the Legislative Decree n. 230/1995. The issuance of these criteria will allow the Implementer to start the siting procedure with the definition of a Chart of potentially suitable sites.

As described in the Report, planned measures highlighted in the past Review Meeting are in progress. Granted decommissioning licences regulate the development of different activities according to specific decommissioning and dismantling projects to be approved by ISPRA. Several activities are reported as being in progress or planned in the NPPs to treat, condition and store radioactive waste.

The updating of technical Guides by ISPRA to regulate such activities has been conducted, in particular three technical Guides are under preparation related to Storage of radioactive waste, Decommissioning operations and Criteria and Methodology for Release of Materials. They reflect the experience gained in the licensing activities already performed and take into account 
WENRA reference levels. These Guides will be issued following the procedure stated in the national legislation.

With regard to the implementation of most recent concepts of safety management by Licensees, it is reported how the Safety Management System of the national Implementer is evolving to adhere to an integrated management system model (i.e. IAEA GS-R-3).

This National Report was prepared on behalf of the Italian Government by the Department for Nuclear, Technological and Industrial Risk of the Italian Institute for the Environmental Protection and Research (ISPRA), that is the Italian National Regulatory Body. 

Section B. Introduction 



\section{Introductory Remarks}

This Report is intended to provide an updating of the Italian National Report issued in 2010. To organise its content, the following aspects have been considered:

- the changes in policy as well as in national nuclear safety laws, regulations and practices since 2010, when the fifth National Report was issued;

- the topics identified during the fifth Review Meeting;

- information on technical issues related to the Fukushima accident and to the implementation of the IAEA Action Plan on Nuclear Safety as applicable to the state of the nuclear installations in Italy, also and taking into account the updating provided in 2012 through the Report for the Extraordinary Meeting.

The above considerations led to prepare a self standing document. To this aim, the Report provides a general update of the "article-by-article review", as applicable to the Italian scene, with Annexes integrating the pieces of information provided in the main text.

\section{Italy's Nuclear Activities Policy}

Since the abandonment of nuclear power followed to the referendum of November 1987 and the consequent definitive shut-down of the four Italian nuclear power stations (i.e. Garigliano, Latina, Trino and Caorso), no significant change of policy has occurred on the matter until 2009 when the Government decided to reopen the nuclear option by envisaging the construction of new installations in the coming years. A new legislation was promulgated in July 2009 (Law $\mathrm{n}$. 99/2009), followed by an implementation decree (Legislative decree n. 31/2010), in order to regulate the process to start a new nuclear programme. As already said, following the Fukushima Daichi NPP event and as result of a national referendum, the process to start a new nuclear programme was stopped and the new legislation consequently amended. This report will therefore deal with the situation related to existing Nuclear Installations and to the associated decommissioning programmes.

In the past years specific policy statements were issued by the Government to address the need of keeping up-to-date competences and capabilities on nuclear safety related matters by National State R\&D organisations, as well as by the National Regulatory Body, Universities, State owned Companies and selected Industries. These policies were essentially aimed at maintaining effective nuclear infrastructures suitable to ensure a safe conduct of the decommissioning activities, safe management of spent fuel and radioactive waste, investigation of safer nuclear plants concepts and participation in international debate on nuclear safety. In addition, a proper consideration was given to keep up structures and technical competencies in order to maintain adequate emergency preparedness capabilities, in particular, in relation to nuclear accidents potentially affecting reactors located in the neighbouring countries. 
Since 1999 SOGIN (Società Gestione Impianti Nucleari) S.p.A., whose single shareholder is the Ministry of Economy, is managing the decommissioning of the four Italian NPP's definitely shutdown. In 2003 also the fuel fabrication and experimental fuel cycle installations licenses were transferred to Sogin in order to manage their decommissioning up to the end states (green field). The primary mission of SOGIN is the decommissioning of all Italian nuclear installations according to a single step strategy, as well as the safe management of the spent fuel and radioactive waste. Strategic and operational guidelines are given by the Italian Government.

According to Legislative Decree $n^{\circ} 31 / 2010$, SOGIN has been also entrusted of siting, construction and operation of the national radioactive waste repository. A special fund allocation for financing all these activities is ensured by means of a specific levy on the price of the electricity.

Until 1999, a safe enclosure strategy had been implemented for the decommissioning of the NPP's after their definitive shutdown. Following the subsequent governmental decision to move into a decommissioning strategy until the unconditional release of the sites in 20 years period, involving the dismantling of structures and components, new plans have been submitted by the licensee to the involved authorities for approval and authorization. At present, decommissioning regulatory processes have been completed for two NPP's and for the other two authorizations are expected to be granted in the near term. It is to be noted that the Italian legislation regulates the decommissioning of nuclear installations as a comprehensive set of actions and the authorisations can be granted either in several steps (phases) accomplished in planned and definite intermediate states or in a single phase. The multiple phase approach, however, is accepted on condition that the proposed subdivision into phases is shown to be part of an overall decommissioning plan leading up to the unconditional release of the site (green field) and defining, inter alia, the destination of resulting radioactive waste. In addition, current regulations require that the decommissioning plans are authorised only after the positive closure of the environmental impact assessment procedure.

On the other hand, the experience resulting from the management of NPP's shutdown since many years clearly indicated some priorities before starting the bulk of the dismantling activities, in particular the need to remove the spent fuel still present in the pools and to manage (conditioning and storage) operational waste already existing on the sites. To this aim, as discussed more in detail in the following sections, the transfer of the spent fuel abroad for reprocessing is in an advanced phase and several projects aimed at conditioning existing waste and new interim waste storage facilities on the sites have been realized or in progress. These facilities are in several cases also intended to accommodate decommissioning waste for the period between the completion of their conditioning process and their transfer to the national repository.

Law provisions establish the possibility to authorize specific activities related to decommissioning and dismantling before the approval of the overall decommissioning plan 
(decommissioning license), provided that benefits to safety and radiation protection are properly demonstrated and the overall decommissioning plan has been submitted. On this basis, several preliminary decommissioning activities have been therefore conducted on the sites and others are in progress. These activities are mainly related to the treatment and conditioning of existing waste, to the decontamination of some systems and components, to the removal of piping isolation, to the modification of obsolete equipment to the preliminary dismantling of systems and components. They are however not related to the nuclear island whose dismantling is strictly connected to the availability of adequate storage capacity for the resulting materials.

As discussed in the fifth Report, difficulties were encountered by the Government in finalising the siting of a national site for waste storage localisation and, in the absence of a defined perspective, some local Administrations opposed the construction of on-site temporary radioactive waste storage facilities. This has caused some delay in the timing of the decommissioning and dismantling activities. The legislative decree $n^{\circ} 31 / 2010$ identified new general procedures and licensing steps for the siting of the national repository for radioactive wastes; such decree has been designed and issued also with the purpose to overcome the past difficulties.

The status of the decommissioning activities at the four NPPs is reported in the Annex 1.

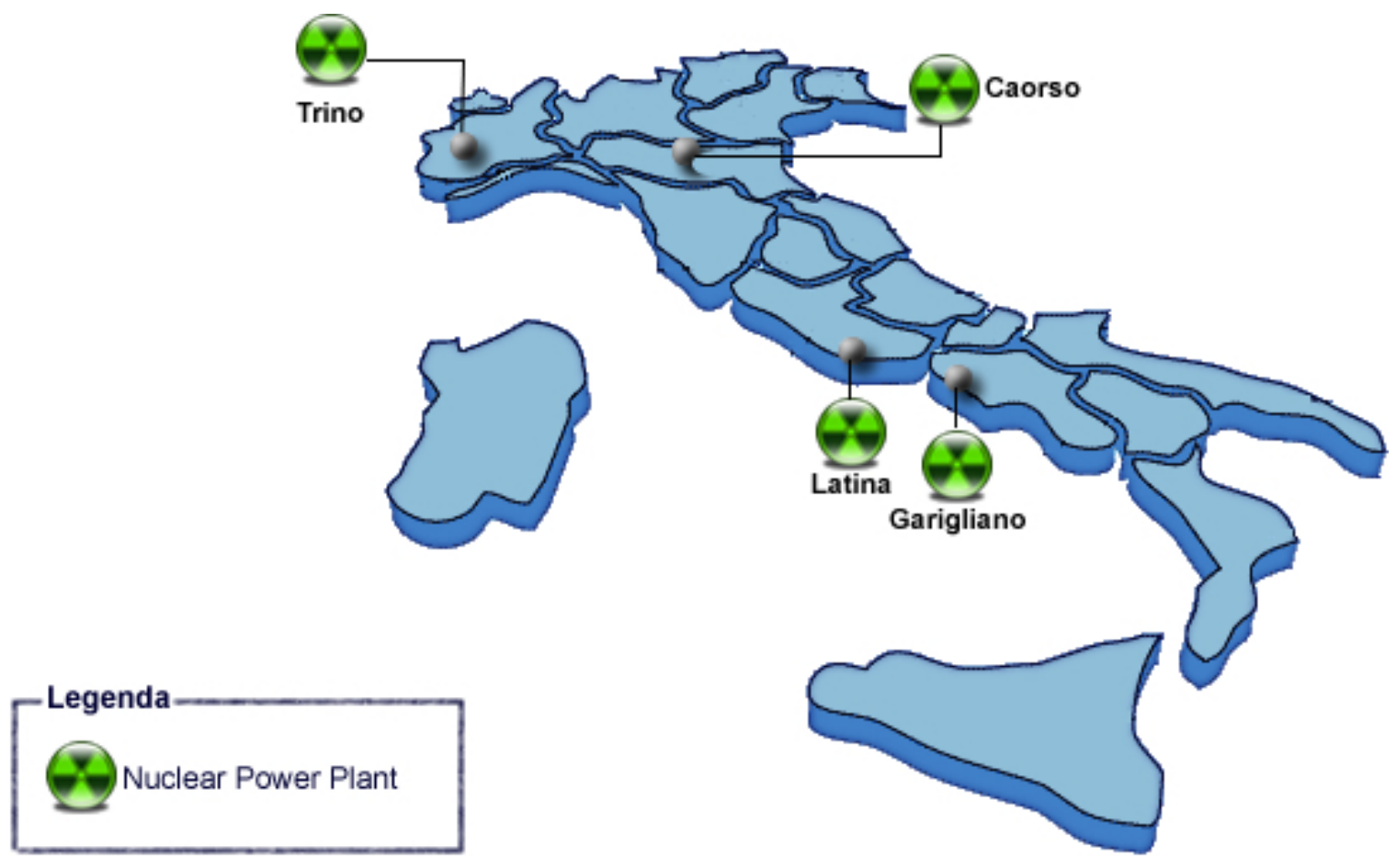

Figure 1: Location of Italian NPPs 


\section{Policy Developments}

\section{Decommissioning policy}

The current national decommissioning policy was established in 2004 when the Ministry of Economic Development (i.e. Ministerial Decree of December 2004) updated strategic objectives assigned to SOGIN according to the following main actions:

a) treatment and conditioning into certified form, in a 10 year time frame, of all liquid and solid wastes, ready to be delivered to the national repository;

b) completion of all the actions needed for satisfying existing spent fuel reprocessing contracts;

c) feasibility evaluation of temporary export of the spent fuel still present in NPPs' for its reprocessing and of interim storage on the sites - evaluation of the short and long term costs, of the safety and environmental protection requirements and of the time needed implementation of the necessary actions;

d) a single step decommissioning of all nuclear power plants and nuclear fuel cycle facilities in a 20 years time frame, pending the operation in due time of a national facility for disposal and long term storage of radioactive waste.

In the context of the on going authorization process of the NPPs decommissioning plans, the Regulatory Body took the position that before the start up of dismantling activities of the nuclear island, in the case of unavailability of a national facility for radioactive waste storage, the licensee will have to provide adequate on site interim storage capacity for the amount of waste foreseen to be produced. The building and operation of associated interim storage facilities need to be authorized by the competent Italian authorities.

\section{Spent fuel management policy}

Since the beginning of its nuclear programme, Italy had pursued the option of reprocessing abroad the spent fuel produced in its NPP's. After the political decision to stop all nuclear power activities, the shipments abroad of spent fuel for reprocessing were suspended with the last shipment to UK occurred in 2005, in the frame of a service agreement already in place.

The opposition of local communities and authorities to the choice of the on-site dry storage (Ministerial Decree of May 2001and December 2004 above mentioned), led the Government to reconsider the option of reprocessing abroad all the spent fuel still present (Directive of the Ministry of Economic Development, March 2006).

In particular, apart from the Uranium/Thorium fuel stored at the ITREC facility, SOGIN was charged to establish reprocessing agreements for all the remaining spent fuel presently stored in Italy, including the Italian part of spent fuel resulting from the Superphoenix experience.

Such a decision has become a part of the Inter-Governmental Agreement signed with the French Government on November 26, 2006, followed by a contract that SOGIN S.p.A. assigned to Areva Nc on May 9, 2007. The Agreement envisages the return to Italy of the radioactive 
waste resulting from the reprocessing activity. In connection with the Agreement a road map has been also defined concerning the timing of the spent fuel transfer operations to France and the return of wastes to Italy as well as the different actions to be implemented on the legislative and implementation side to make available a storage facility for the waste returning from France.

Waiting for the transfer abroad for reprocessing, the spent fuel is being maintained in the storage pools. With regard to the NPPs, spent fuel has been removed from Garigliano and Latina NPPs since many years. The transfer campaign from the Caorso site to France for reprocessing was completed in June 2010. Spent fuel for a total amount of about 30 tons is still present in the Trino NPP site and Avogadro AFR facility and its transfer abroad is expected to be completed by 2015. Its safe management continues to be performed according to existing licence conditions and technical specifications.

\section{Radioactive waste management policy}

Most of the radioactive waste existing in Italy has been produced in the past operation of the nuclear installations. The main additional waste to be managed in the future will come from the decommissioning activities, as well as from the re-entry in Italy of the conditioned high and intermediate level waste resulting from the reprocessing abroad of the spent fuel. At present, almost all the waste originated by the past nuclear programme is stored in the site of each individual installation where it was generated.

Several initiatives have been taken in the past years to investigate the possible solutions for the siting of a national storage facility. It is worth to mention the so called "Site Task Force" coordinated by ENEA, which operated in 1999-2000 with the mandate to prepare a list of potentially national qualified sites, and the work done by a Parliament/Region Commission charged to prepare a document aimed at proposing a possible path to identify a site and to reach the necessary consensus.

In connection with the mentioned Agreement for the reprocessing of the $235 \mathrm{t}$ of spent fuel still stored in Italy, the commitment of the Italian Government to make a national site available in due time to host the resulting waste that will be returned to Italy has also to be highlighted. In March 2008, the Ministry of the Economic Development appointed a Committee with representatives of Ministries, Regions, ISPRA and ENEA, having the mandate to define the procedures for identifying suitable areas and for selecting a national site for the storage of radioactive waste. A report from this Committee was issued in September 2008. More recently, also in connection with the road map associated to the above mentioned Agreement, the Legislative Decree $n^{\circ} 31 / 2010$ establishes the new procedure for the localization and the construction of a national repository for the LLW disposal and the ILW-HLW long term storage, and assigns to Sogin the role of the Implementer responsible for the construction and operation of the national repository. 
Legislative Decree $n^{\circ} 31 / 2010$ also assigns to Sogin the responsibility to propose areas suitable for the identification of the site based upon criteria established by the IAEA and by the new national Agency for Nuclear Safety and taking into account results of Strategic Environmental Evaluation. The steps to be made in order to realize a national storage facility are described below, together with the timeframes to perform each of them.

At first, a list of suitable areas is proposed by the Implementer (SOGIN S.p.A.). Such a list should be defined based upon technical criteria as reported in IAEA standards and as established by the new Italian Agency for Nuclear Safety (ASN).

After this preliminary selection, a period of 60 days for a public consultation is foreseen. A public presentation through a seminar by inviting the central and local interested Administrations will be organized by Sogin in this period.

Once the potential sites are approved by the Regulatory Authority, SOGIN invites the involved Regions to present its interest within 60 days. Once one (or more) Region shows interest, Sogin performs its extensive investigations on the site and within 4 months submit a request for authorization to the Regulatory Body, which express its judgement within 1 year. The license is foreseen to be unique (the authorization is given for construction, operation and closure).

In the case of lack of interest, Sogin will submit to the Ministry of Economic Development the list of the candidate areas indicating the first three more suitable sites, and within $\mathbf{3 0}$ days an interinstitutional Committee will be created, with the participation of representatives from different Ministries and Regions.

Due to the suppression of the new Nuclear Safety Agency (established with the Law 99/2009, but not yet applied), in 2012 ISPRA has been charged with the task to develop technical siting criteria for the identification of potential area where to realize a LLW near surface disposal facility and an Interim storage for ILW and HLW. A first draft of Technical Guide has been prepared and a process of international review has been conducted. A peer review of the technical guide has been requested to IAEA and the Agency final report has been transmitted in September 2013. Technical exchange have also taken place with Nuclear Safety Authorities of France, Switzerland, Belgium and Slovenia. The Technical guide will be issued according to the procedure defined in the legislation.

Waiting for the availability of a national repository, radioactive waste are being stored in the nuclear installations of origin. Action plans are in progress to enhance the safety level of waste by implementing specific treatment and conditioning projects, by refurbishing existing buildings or by realizing new storage facilities on the sites. New facilities will also be used to ensure temporary storage capacity for waste resulting from decommissioning activities. The 
implementation status of the above referred action plans is reported in the Annex 1 (list and status of nuclear installations in Italy).

\section{Legislative and regulatory framework}

In the past three years the following developments regarding the legislative and institutional framework have taken place.

A reported in the previous report in the frame of a general reorganization of administrations under the aegis of the Ministry of Environment, in 2008 the National Institute for Environmental Protection and Research (ISPRA) was established (Law $n^{\circ}$ 133/2008) by merging the previous Agency for Environmental Protection and Technical Services (APAT) with other administrations operating in the field of environmental protection. As a consequence of that also the functions and duties as Regulatory Body in the nuclear field previously assigned to APAT were transferred to ISPRA. These functions and duties are fulfilled by the Nuclear Department of the Institute.

It has already been said that, in connection of the new nuclear programme, Law n 99/2009 established new provisions in the field of energy and delegated the Government to promulgate new legislative decrees in order to reorganize the framework regulating the localization in the national territory of new installations for the production of nuclear energy.

Among other provisions, Law 99/2009, in Article 29, established a new Nuclear Safety Agency with the role of Regulatory Body. also stating that in the transition phase necessary for the new Agency to become operative the regulatory body functions would have been continued to be performed by the Nuclear Department of ISPRA.

In particular, in the area of the peaceful use of nuclear energy, the duties of the new Agency are related to the issuance of technical rules and to the approval and control of activities. Moreover, the Agency is charged of the control of the management and storage of wastes coming from NPPs, medical and industrial facilities, of the inspection activities on construction, operation and safeguards.

The Agency will be the only national authority responsible for nuclear safety and radiation protection and:

- its advise is obligatory and binding for any authorization released by public administrations;

- $\quad$ its inspectors are authorized to gain access to installations and documents, and to take part in the testing activities as required;

- $\quad$ can require the submission of data, information and documents;

- $\quad$ can assess fines, suspend licenses and propose its repeal;

- $\quad$ inform the public; 
- defines and control the procedures that licensees have to implement for the plants dismantling or for the waste management.

As said, following the Fukushima Daichi NPP accident and a national referendum in June the new nuclear programme was stopped and the above mentioned legislative provisions established for its implementation amended. Only provisions regulating the siting and construction of a national facility for the disposal of low level waste and the long term storage of high level waste as well the establishment of a Nuclear Safety Agency were maintained. Subsequently, in December 2011, with law n. 214/2011 the new Agency was cancelled and its duties and functions were assigned to ISPRA waiting for a reorganization of the national regulatory function to be established by a joint decree of the Ministry of economic development and of the Ministry of environment.

It has to be also highlighted that in October 2011 the Legislative Decree n. 185 was issued to transpose in the national legislation EU Directive 2009/71/EURATOM establishing a Community framework for the nuclear safety of nuclear installations.

\section{List of Nuclear Installations in Italy}

A short description of the status of the four NPPs is reported in Annex 1.

Background historical information on Italian Nuclear Programme are summarised in Annex 2.

\section{Italian Participation in International Activities to Enhance Nuclear Safety}

As referred in the previous Reports, Italy has traditionally been active in international nuclear cooperation within IAEA, OECD/NEA, EU and FORATOM as well as in bilateral contexts. An active contribution to these activities is considered to be important the keeping up-to-date the national competencies and capabilities in the safety and in the technology of nuclear installation as well as the promotion of maintaining and updating the nuclear safety culture at national level.

\section{Regulatory Body}

In the framework of a regulatory system, it is recognized that the international cooperation provides also a significant contribution to the quality of the national safety and radiation protection regulatory work. In such a context the experienced cooperation by ISPRA has primarily regarded regulatory issues dealt with in the International Organisations. In addition to the activities performed to fulfill the above obligations on the Conventions, it is mentioned the participation of ISPRA experts in the production and updating of IAEA safety standards as members of the safety standards Committee (NUSSC, WASSC, RASSC, TRANSSC). 
As member of the EU Institutions committees facing the nuclear regulatory issues, ISPRA fully takes its responsibility in contributing to the enhancing of the nuclear safety as a main objective of the EU international policy, not only through an active participation at level of production of Commission binding instruments (i.e. WPAQ of the Council) but also through direct participations in all the fora where cooperation actions in the nuclear safety field are proposed and evaluated.

In its Regulatory Authority institutional role, ISPRA is member of ENSREG and actively participates in all the ENSREG activities. In this regard the active participation of ISPRA in the 2012 process of the post-Fukushima Peer Review on the Stress Tests is to be mentioned.

In addition, ISPRA is a member of the Western European Nuclear Regulators Association (WENRA) and has actively participated in the comparison of safety requirements of the different member countries, against agreed reference levels, as basis for harmonisation.

Together with all the other WENRA Members, ISPRA has used the outcomes from this project for establishing the national action plan to correspondently update its basic safety regulations. mainly addressing issues related to decommissioning and waste management.

ISPRA expects that on next years the production of national nuclear regulation, even remaining a national responsibility, will be largely driven by regional and international contexts. The need of ensuring international participation and the work on correspondingly reviewing the national regulation will require an increase of national resources. Major international references for pursuing the establishing of common safety standards and regulatory practices (global nuclear safety regime) are the IAEA through its policy and the recently established action plan and other international organisations such the OECD/NEA. At EU level, the reference is represented by the current nuclear Safety Directive (2009/71) and the recent entry into force of the Directive on the management of spent fuel and of radioactive waste. A revision process of the Safety Directive proposed by the Commission in the light of the Fukushima accident has been also started at the Council on June 2013.

It is expected that the Fukushima accident will increase the role of the $\mathrm{EU}$ in the nuclear regulatory field. In fact the potential trans-boundary radiological consequences of a nuclear accident could exceed the emergency preparedness and response capability of an even effective cooperation and mutual assistance established between neighbouring countries. This would therefore require both the enhancing of emergency preparedness and response provisions in place in the Member States as well as an appropriate coordination on a large scale which can be ensured only at regional and international level. In our view the EU should take such a regional coordination role to be conceived so to fit with the IAEA international role in the field of emergency preparedness and response. 
Among the actions initiated after the Fukushima accident, Italy has communicated to the IAEA an invitation at receiving an IRRS mission in 2015. Such a decision responds to the need to comply with the obligation established in the Safety Directive and with the willing to submit to a third party review the national regulatory system..

\section{International support programmes}

Italy has continued its technical participation in international programmes of assistance to the eastern European Countries in the frame of TACIS, now INSC, extended to Mediterranean Countries, and in the frame of IPA (Instrument for Pre Accession to European Union). In this context, training and tutoring activities on decommissioning and waste management performed by ISPRA in the last years at its premises and at NPPs sites are to be mentioned.

In addition to the ISPRA cooperation in the regulatory assistance projects, the national nuclear industry participated both in realisation activities already in progress (e.g.: Ansaldo for Rumanian Chernavoda units and for the supply of major components to new reactors (e.g. AP 1000) under construction) and in international tenders for the realisation of new nuclear installations (e.g. ENEL for Bulgarian Belene and Romanian Chernavoda) and of NPPs on-site assistance programmes (e.g. SOGIN for Armenia/Medzamor, Mexico/Laguna Verde).

ENEL participation in abroad nuclear activities includes the $66 \%$ of Slovenske Elektrarne, (including Mochovce 3 and 4 under construction), and of 92\% of Endesa, Spain.

The national participation in the international nuclear research projects is primarily ensured by ENEA, involved in particular in EU research programmes. 
Section C. Compliance with articles 4 to 19 

Article 4. Implementing measures

Each Contracting Party shall take, within the framework of its national law, the legislative, regulatory and administrative measures and other steps necessary for implementing its obligations under this Convention.

The Italian Legislative and Regulatory framework has been long in force (since the early $60^{\text {ties}}$ ), as discussed in detail in the first four Reports and summarized in the present Report. Being this framework quite complete and updated according to the development of the national nuclear programme and of new European legislation, no further step is deemed necessary because of the Convention. 
Article 5. Reporting

Each Contracting Party shall submit for review, prior to each meeting referred to in Article 20, a report on the measures it has taken to implement each of the obligations of this Convention

The present Report constitutes the sixth Italian Report issued in compliance with Article 5 of the Convention. 
Article 6. Existing Nuclear Installations

Each Contracting Party shall take the appropriate steps to ensure that the safety of nuclear installations existing at the time the Convention enters into force for that Contracting Party is reviewed as soon as possible. When necessary in the context of this Convention, the Contracting Party shall ensure that all reasonably practicable improvements are made as a matter of urgency to upgrade the safety of the nuclear installation. If such upgrading cannot be achieved, plans should be implemented to shut down the nuclear installation as soon as practically possible. The timing of the shut-down may take into account the whole energy context and possible alternatives as well as the social, environmental and economic impact.

\subsection{Overview of major events since the last Report}

As indicated in all previous Report, Italy decided the shutdown of its NPPs in 1987. The installations were not shutdown for specific safety reasons but following a decision of the Government taken on the basis of the results of a national referendum.

Safety issues currently of concern for the four Italian NPPs are therefore those related to decommissioning activities as well as to the safe management of the limited amount of spent fuel still on the sites and of radioactive waste, which are covered under the Joint convention on the safety of spent fuel and radioactive waste management.

More information on the state and activities currently performed at NPP is reported in Annex 1. It has to be highlighted that in 2012 the decommissioning license has been granted to the Trino and Garigliano NPPs, while the related licensing procedure is expected to be completed in 2013 for the Caorso NPP and in 2014 for the Latina NPP.

In the context of the licensing process the overall safety status of the installation is reassessed taking into account the decommissioning operations to be conducted. The decommissioning license also establish specific conditions according to which activities having relevance for nuclear safety and radiation protection have to be approved by the Regulatory Authority on the basis of specific Detailed Projects or Operational Plans with the pertaining safety analysis. The SAR report is also requested to be maintained updated. 
Article 7. Legislative and Regulatory Framework

1. Each Contracting Party shall establish and maintain a legislative and regulatory framework to govern the safety of nuclear installations.

2. The legislative and regulatory framework shall provide for:

i. the establishment of applicable national safety requirements and regulations;

ii. a system of licensing with regard to nuclear installations and the prohibition of the operation of a nuclear installation without a licence:

iii. a system of regulatory inspection and assessment of nuclear installations to ascertain compliance with applicable regulations and the terms of licences;

iv. the enforcement of applicable regulations and of the terms of licences, including suspension, modification or revocation.

\subsection{Nuclear safety legislation and regulatory framework}

The current Italian legislative and regulatory framework related to nuclear safety and radiation protection is the result of an evolution of rules and provisions that begun in the early $60^{\text {ties }}$ and that took into account the experience of licensing and operation of NPPs of different types and generations and of other nuclear installations.

The Italian regulatory system is made up of three types of rules of different legal force depending on their origin:

- legislation proper, that is Acts and legislative decrees, and governmental or ministerial decrees;

- technical guides;

- technical standards.

\subsubsection{Legislation and ministerial decrees.}

In the Italian regulatory system the source of legally binding rules must be either an act of Parliament or a Legislative Decree issued by the Government thus empowered by Parliament. The Government can also issue governmental or ministerial decrees binding in law. The practice of laying down numerical limits and minute regulations in decrees issued by the Executive is very frequent in particular areas relative to Radiation Protection. An important feature of legally binding rules concerning Nuclear Safety and Radiation Protection in Italy is that contravention to obligations by operators and/or users constitutes a misdemeanour and 
entails a penal sanction; compliance can be enforced by means of criminal proceedings after due process of law.

The main corpus making up, inter alia, the Italian system are itemised below, as regards Acts and Legislative decrees:

- Act no. 1860 of 31 December 1962: published in the Italian Republic's Official Journal no. 27 of 30 January 1963, as amended by the President's Decree no. 1704 of 30 December 1965 and by the President's Decree no. 519 of 10 May 1975;

- Presidential Decree no. 185 of 1964: "Safety of plants and protection of workers and general public against the risk of ionising radiation associated to the peaceful use of Nuclear Energy replaced in 1996 by the Legislative Decree no. 230/1995, described below;

- Act no. 393/1975: which contains Administrative rules on the selection of the site for NPPs;

- Presidential Decree no. 1450/1971: which contains Requirements and procedure for the acquisition of the operational personnel licences;

- Presidential Decree no. 519/1975: "Civil responsibilities in the field of nuclear safety";

- Legislative Decree no. 230/1995: published in the Supplement to Italian Republic's Official Journal no. 136 of 13 June 1995, which has been in force in Italy since January 1st 1996 - and replaces the Presidential Decree no. 185/1964, the previous radiation protection act -, implements six EURATOM Directives on radiation protection (EURATOM 80/836, 84/467, 84/466, 89/618, 90/641 and 92/3). Legislative Decree no. 230/1995 needs a series of Government and Ministerial Decrees;

- Legislative Decree no. 241/2000: which has transposed European Union (EU) directive 96/29/Euratom laying down basic safety standards for the radiation protection of workers and the public; the standards laid down in the directive incorporate the 1990 Recommendations of the International Commission on Radiation Protection (ICRP) into EU radiation protection legislation. Legislative Decree no. 241/2000 has modified and integrated Legislative Decree no. 230/1995, the latter constitutes the main piece of legislation laying down radiation protection requirements for workers and the public;

- Legislative Decree no. 257/2001: which modified certain details in Legislative Decree no. 241/2000 concerning requirements for notification and authorisation of non nuclear installations where ionising radiation is used for industrial, research and medical purposes;

- Legislative Decree no. 23/2009: which has transposed EU directive 2006/117/Euratom on the supervision and control of shipments of radioactive waste and spent fuel; Legislative Decree no. 23/2009 has modified pertinent administrative provisions previously contained in Legislative Decree no. 230/1995 concerning the transboundary 
shipments of radioactive waste. Legislative Decree no. 230/1995 now contains new provisions on the supervision and control of shipments of spent fuel.

- Law $n^{\circ}$ 99/2009, related to the process to start a new nuclear programme, in Article 29, establishes a new Nuclear Safety Agency with the role of Regulatory Body. As already mentioned, the Agency will be made by the resources of the Nuclear Department of ISPRA and by resources from the Agency for New technologies, Energy and sustainable development (ENEA). As said the new Safety Authority has been cancelled in 2011 before becoming operative.

- Legislative Decree $n^{\circ} 31 / 2010$ related to the future nuclear development in Italy, provides criteria for the site selection procedure with the involvement of local administration, for the approval and for the compensation of the local municipality. The Decree includes also provisions for the site selection procedure of the national site for radioactive waste disposal giving the responsibility to SOGIN.

- Legislative Decree $n^{\circ}$ 185/2011 which transposes the EU Directive 2009/71/Euratom establishing a Community framework for the nuclear safety of nuclear installations. Legislative Decree $n^{\circ}$ 185/2011 has modified and integrated Legislative Decree no. 230/1995.

- Law $n^{\circ} 27 / 2012$ on the economic development, through the Art. 24, establishes a new procedures to reduce the timing of the licensing phases for decommissioning activities with a strong involvement of local administrations.

On the consequences of the Fukushima accident, the Referendum held on 12 June 2011 definitely sanctioned the abandon of the nuclear power development programme in Italy started in 2009 and the following legislative provisions were issued:

- Legislative Decree $n^{\circ}$ 41/2011 amended the Legislative Decree $n^{\circ}$ 31/2010 with reference to the future nuclear development in Italy.

- Law $n^{\circ}$ 75/2011 that modifies all the provisions given in the Law $n^{\circ}$ 99/2009 and in the Legislative Decree $n^{\circ} 31 / 2010$, as amended by the Legislative Decree $n^{\circ} 41 / 2011$, concerning the development of new NPP in Italy, relinquishing the nuclear development in Italy. The provisions for the development of the national site for LLW disposal and ILWHLW interim storage has been confirmed. Furthermore, the Law $n^{\circ} 75 / 2011$, abrogating the Article 9 of the Legislative Decree no. 230 of 1995, slightly modifies the regulatory process by cancelling of the "Technical Commission on Nuclear safety and Radiation Protection". This Commission was entitled to formulate an independent technical advice to ISPRA during the assessment process connected to the granting of licences, authorizations and approval of detailed designs.

- Law $n^{\circ}$ 214/2011 that abrogates the Nuclear Safety Agency (created with the Law $n^{\circ}$ 99/2009, but never applied) and the functions have been temporary assigned to ISPRA 
(that in fact continue its work as nuclear authority) waiting for a definitive asset of the regulatory organization.

A series of Governmental and Ministerial Decrees have also been made in implementation of the Act no. 1860/1962 and the Legislative Decree no. 230/1995.

The main functions of the Regulatory Body, as better identified under article 8, were in the past entrusted to the Directorate for Nuclear Safety and Health Protection (DISP) of CNEN, later on ENEA. Such functions, together with staff, technical structures, equipment and financial resources of DISP, were transferred to ANPA and to APAT, now ISPRA, which is therefore now discharging the main functions of National Regulatory Body, among its other duties concerning the Environment Protection field.

The Acts of legislative force on the institution and subsequent re-organisations of the Regulatory Body are listed below:

- Act no. 933/1960: on the establishment of the National Committee for Nuclear Energy (CNEN);

- Act no. 84/1982: on the establishment of the State Agency for new technologies, energy and environment (ENEA);

- Act no. 61/1994: on the establishment of the National Agency for the Environment Protection (ANPA).

- Legislative Decree $n^{\circ}$ 300/1999 and President of the Republic Decree ${ }^{\circ}{ }^{\circ}$ 207/2002: on the establishment of APAT, by merging ANPA with other national Technical Services;

- Act no. 286/2006: on the reorganisation of APAT as a legal entity of public administration, endowed with new institutional Organs;

- Act no. 133/2008: on the establishment of the Institute for the Environmental Protection and Research (ISPRA).

\subsubsection{Technical guides}

This issuing of technical guides is assigned in Law to ISPRA, by article 153 of the Legislative Decree no. 230/1995.

Technical guides set up technical criteria to be taken into account by Operators in the siting of nuclear installations, submittal of specific projects for approval, conduct of operations as well as rules of good practice. Compliance with Technical Guides is assessed during licensing process and inspection activities. A set of 28 technical guides have been issued on Safety and Radiation Protection matters ranging from licensing procedures to detailed technical guidance.

In addition, the existing wealth of international recommendations, such as those reported in IAEA (International Atomic Energy Agency) and ICRP (International Committee on Radiological Protection) publications, is largely used in the Italian system.

The list of the most important Technical Guides is reported in Annex 3. There is a programme to update these technical guides in the near future, essentially based on the national action plan 
established in the framework of WENRA activities related to the development of safety reference levels. Draft technical guides for decommissioning activities and waste storage have been developed taking into account past regulatory experience and are expected to be issued by the end of this year according to the procedure defined in the Legislative Decree $n$. 230/1995. and are used for regulatory review and assessment activities.

\subsubsection{Technical standards}

These standards are mainly published by UNI (Ente Nazionale Italiano di Unificazione), the Italian National Standards Body. Selected standards are listed in Annex 3.

Other Standards often used were those published by CEI (Comitato Elettrotecnico Italiano) and by ISO (International Standards Organisation).

Standards documents are developed within an Expert Group and approved by UNI and/or CEI Technical Committees.

Standards developed within the above mentioned Bodies are intended to reflect the broad consensus of industry and research experts in the specific fields. These standards are thought to represent industrial good practice.

Moreover, in the design, construction and operation of nuclear installations, other rules such as the ones concerning fire fighting, pressure components integrity, labour and health apply. Among the other, foreign technical standards are often adopted and endorsed, on a case by case basis.

A wider list of the main different rules which comprise national Legal and Regulatory framework is reported in Annex 3.

\subsection{National safety requirements and regulations for radiation safety}

Information reported under article 7.1 and in Annex 4 provide a comprehensive picture of the national safety requirements and regulation for radiation safety.

\subsection{Licensing System}

Article 6 of Law n. 1860/1962 establishes that the operation of nuclear installations has to be authorized by the Ministry of Industry (now Ministry of Economic Development). Authorization is granted according to provisions established in Title VII of the Legislative Decree n. 230 of 1995, based upon the technical advice of ISPRA, which is formulated as result of the assessment of the safety case filed by the applicant. Title VII also define the licensing procedure relevant for each phase of the nuclear installation life (i.e. from siting to decommissioning). In relation to the current status of all the nuclear installations, the decommissioning licensing procedure is hereinafter described in detail. 


\subsubsection{Licensing process for decommissioning}

As far as decommissioning activities are concerned, the licensing procedure is established in articles 55-57 of Title VII of the Legislative Decree n. 230/1995

The decommissioning of a nuclear installation is subject to prior authorisation by the Ministry of Economic Development in accordance with other competent Ministries (Ministries of Environment, Interior, Labour, Health) and the Region concerned. A binding technical advice of ISPRA is requested by law. Such ISPRA' advice includes technical specifications as part of the authorization to the nuclear installation decommissioning. The technical advice of ISPRA takes into account observations expressed by different involved Ministries as well as relevant local authorities.

A separate Environmental Impact Assessment evaluation is performed under the coordination of the Ministry of Environment and Territory, acting in consultation with the Ministries of Interior, Labour and Health, ISPRA and the region concerned. Furthermore, any specific management and storage activity of the radioactive waste which will be generated during decommissioning will require, on the bases of a specific decommissioning licence condition, the approval by the Regulatory Body.

Scheme in Fig. 1 represents the licensing process for the decommissioning nuclear installations in Italy.

The authorisation can be issued for intermediate phases leading up to a planned final state. This possible subdivision into intermediate phases must be shown to be part of an overall decommissioning plan, to be submitted with the application for the authorisation concerning the first phase. For each phase the above bodies are sent a plan of the operations to be carried out and a description of the state of the installation, which will primarily include:

- an inventory of the radioactive materials;

- a description of the state of the installation itself at the end of the specific phase;

- a safety analysis concerning the operations to be carried out and the state of the installation itself at the end of the specific phase;

- the intended destination of the resulting radioactive materials;

- an assessment of the radiological impact to the environment of the decommissioning operations;

- a radiation protection programme also for emergency conditions.

In the decommissioning plan the licensee is also required to analyse the situations in which general requirements coming from the operation rules or specific technical specifications will be no longer needed, as well as the systems (safety and non safety related) whose operability is not longer requested.

After receiving the documentation, the other bodies (Ministries of Environment, Interior, Labour, Health, and the Region concerned) transmit their observations to ISPRA that elaborates a 
safety and radiation protection assessment, taking in due consideration such observations, and identifies conditions and specifications. Taking ISPRA assessment into account, the other administrations formulate their final observations and ISPRA sends its final advice, together with technical specifications, to the Minister of Economic Development. In order to gather the observations the Ministry convenes the Conference of Services attended by all the Administrations as specified under the article 55 of the Legislative Decree n. 230/1995. The authorization process is concluded by the Minister of Economic Development who grants the decommissioning licence prescribing compliance with technical specifications established by ISPRA.

Decommissioning operations are carried out under ISPRA surveillance; at the end of the decommissioning operations, the licensee shall send ISPRA an assessment on the operations and the state of the site and of the environment.

After obtaining the advice of ISPRA and of the other bodies on the final assessment, the Ministry of Economic Development can issue specifications concerning the state of the site and of the environment at the end of the decommissioning operations.

Some items characteristic of the Italian decommissioning situation may be highlighted. It is to be firstly noted that the described authorisation process clearly envelopes all possible decommissioning strategies. The earliest applications complying with the Legislative Decree $\mathrm{n}^{\circ}$ 230/1995 referred to a first stage ("safe enclosure"), although it had to be considered as part of an overall decommissioning plan. New applications submitted by late 2001 asking for authorization to the nuclear installations decommissioning were instead intended to cover in a single step the overall programme of activities.

To this respect, it must be mentioned that Italian regulations define decommissioning as "the whole planned actions up to the final dismantling or in any case up to unconditional release (release of site and/or buildings with no radiological constraints)".

Another feature of the Italian administrative system is that a plurality of bodies has a role in the licensing; in fact, each administrative body has to be a guardian of the public interest from its own view point; furthermore, in the Italian system licenses, permits and authorisations are granted by Ministries, even though Agencies or Institutes such as ISPRA play the role of State instruments to which care and supervision of highly technical matters are confided.

On the other hand, the licensing procedure involves the need for ISPRA to collect the opinion of four Ministries (Environment, Interior, Labour, Health), as well as of the region concerned, integrating all the contributions in its assessment; this procedure must be reiterated twice, before ISPRA can deliver its assessment to the Ministry of Economic Development who issues the final act.

One can note that this system provides for a high degree of guaranty even though ways have to be found to make it sufficiently agile and converging, while maintaining its essential feature of seeking the opinion of all public bodies concerned. 
It has to be mentioned that, in order to start the decommissioning activity, a further permission is needed from the Ministry of the Environment, Land and Sea, that is the Environmental Compatibility Statement, required by the Law n. 349/1986.

It has to be highlighted that with the aim of accelerating the decommissioning activities on the sites new provisions have been established with Law $n^{\circ} 27 / 2012$, art. 24 . These provisions indicate a procedure for a single authorisation which take into account also advice of local authorities.

\subsection{Regulatory Inspection and Assessment}

The purpose of the regulatory inspections during the NPPs life (from the construction to the decommissioning) is to verify the fulfilment of the rules coming from the Legislative Decree no. 230/1995 and of the technical specifications which are part of the licence conditions for the specific plant.

According to Art. 10 of the Legislative Decree no. 230/1995, inspections are performed by ISPRA inspectors having the authority to enter any area of the installation, as well as to have access to any relevant documentation. In case of infringement of specific rules of the nuclear act and licence conditions, including technical specifications, ISPRA inspectors are entitled to report to the public attorney of the jurisdiction which the installation belongs to. The purpose of such inspections is to verify the fulfilment of binding rules having legal relevance. Plant walkdown are also frequently performed by other ISPRA technicians with the purpose of achieving data, information and other technically relevant elements to be evaluated with respect to technical regulations. Inspection activities may be ordinary (planned in advance for each technical area) or extraordinary.

ISPRA is entrusted with general inspection powers for installation falling under the provisions of the Act and the Decrees. In the fulfilment of their duties, ISPRA inspectors are vested with police powers, that is, they even have power of seizure on installations deemed to be non compliant with relevant provisions laid down in law.

Apart from ordinary powers given to police, other authorities such as Labour Inspectorate, local Health bodies and regional Agencies for the Protection of the Environment are vested with competence in the fields entrusted to their surveillance.

The Italian compliance and inspection system is based upon the fact that legislation provides for penal sanctions in cases of non compliance; inspectors are required under law to communicate every case of non compliance to the Office of Public Prosecution. 


\subsection{Enforcement}

Article 58 of Legislative Decree n. 230/1995 establishes the procedure according to which, in case of non compliance with the conditions attached to the licence, the Ministry of Economic Development can suspend or revoke the licence or the authorization.

Enforcement of applicable regulations and of licence conditions is ensured on the bases of the sanction system as established in Title V of the Law n. 1860 and in Title XI of Legislative Decree 230/1995. According to Art. 10, ISPRA Inspectors have the authority to request any information they deem relevant to ascertain the compliance of the activities performed at the nuclear installations with the requirements established in the Legislative Decree and in the licence conditions. Inspectors are entitled to report the results of their inspections to the public attorney of the jurisdiction the nuclear installation belongs to.

\subsection{Assessment of Compliance}

The current national legal framework related to safety and radiation protection at nuclear installations is considered fully adequate. 


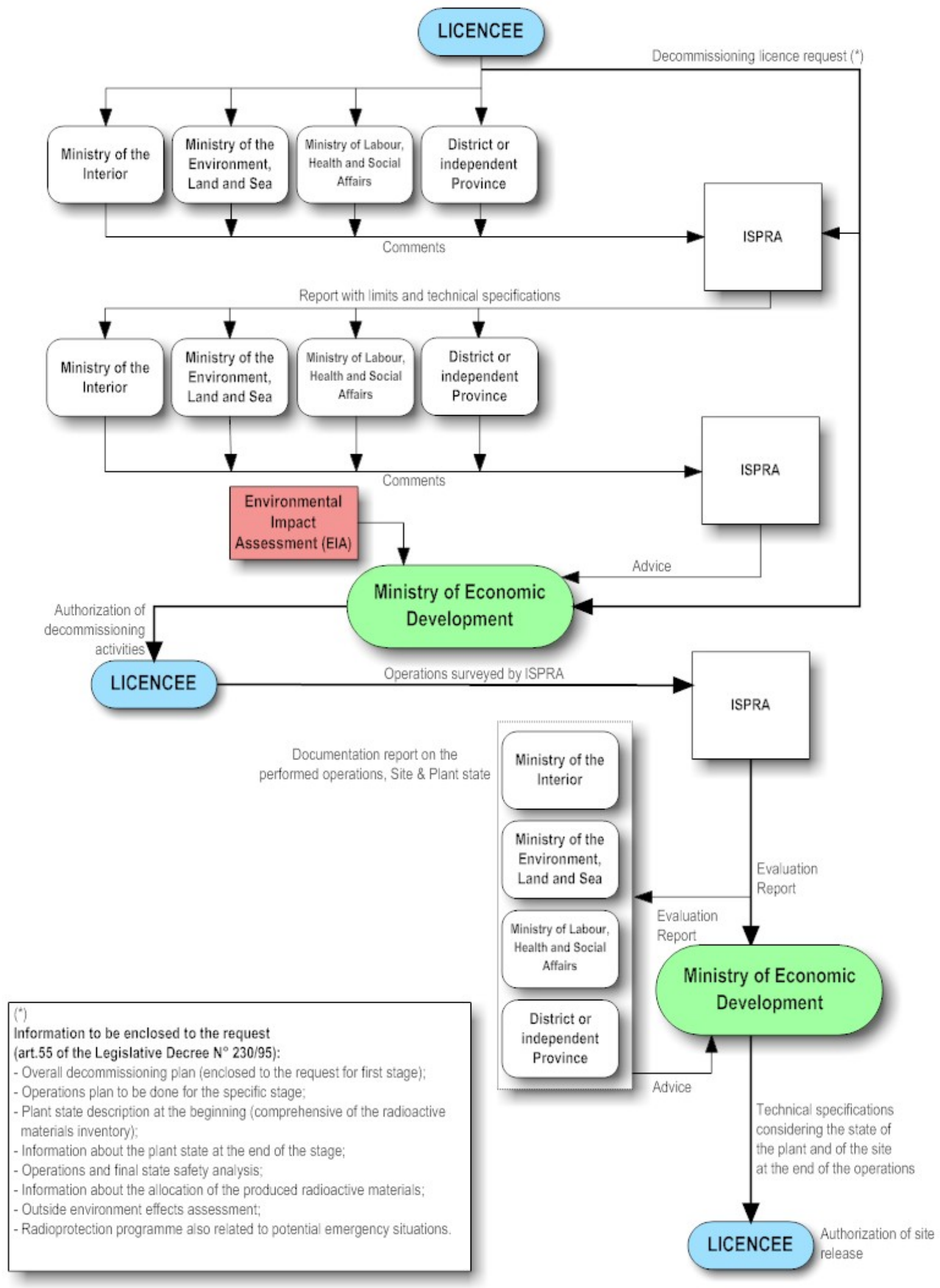


Article 8. Regulatory Body

Each Contracting Party shall establish or designate a regulatory body entrusted with the implementation of the legislative and regulatory framework referred to in Article 7, and provided with adequate authority, competence and financial and human resources to fulfil its assigned responsibilities.

Each Contracting Party shall take the appropriate steps to ensure an effective separation between the functions of the regulatory body and those of any other body or organization concerned with the promotion or utilization of nuclear energy.

\subsection{Authorities responsible for the application of the legislative framework}

The key regulatory functions (rulemaking, licensing, assessment, inspection and enforcement) related to nuclear safety and radiation protection matters, including also NPPs construction and operation as well as safe management of spent fuel and radioactive waste, are exploited in Italy by the following main bodies:

a) The Ministry of Economic Development, in this report defined as the Licensing body, is the authority which grants the licence/authorization for nuclear activities (from the design and construction to the decommissioning and waste disposal) and for major practices involving the use of ionising radiation sources. Authorizations are granted on the basis of the technical advice provided by the Regulatory Body (ISPRA - National Institute for Environmental Protection and Research), and taking into account the advice provided by the Ministries for the Interior, Labour, Health and of the Region where the installation is located, after the issuing of the environmental compatibility statement provided by the Ministry of the Environment, Land and Sea, when applicable;

b) ISPRA - Nuclear Department, in this report defined as the Regulatory Body, is the Governmental body entrusted with the role of Regulatory Authority responsible for the assessment and the inspection activities on nuclear installations, as well as for approving detailed designs of specific activities related to the construction of nuclear facilities, which are part of the general construction licence granted by the Ministry of Economic Development or to the implementation of a plant modification. ISPRA supervises the compliance with the requirements established in the law and in the Ministerial authorization decrees throughout its inspection activity. ISPRA inspectors are entitled by the law with the proper authority to request the licensee any information deemed necessary to ascertain compliance with legal requirements and licence conditions. In case of infringements, ISPRA inspectors reports to the Public Attorney of the jurisdiction the 
installation belongs to ISPRA is also the competent body entitled to support the Governmental rule-making function in the field of nuclear safety and radiation protection. ISPRA is also entitled to issue technical guides pertaining the different operational aspects of the regulatory process. The Regulatory Body functions in ISPRA are performed by the Nuclear Department. It has also to be mentioned that duties and responsibilities assigned to ISPRA include supervision activities on safeguards and physical protection, the exploitation of a technical support function in the field of emergency preparedness and of a control function in the field of environmental radioactivity.

In 2011, the regulatory framework has been modified with the abrogation of the "Technical Commission on Nuclear safety and Radiation Protection". This Commission was entitled to formulate an independent technical advice to ISPRA during the assessment process connected to the granting of licences, authorizations and approval of detailed designs.

It has to be noted that, as provided by the Law $n^{\circ} 214 / 2011$, the new Nuclear Safety Agency has been abrogated (created with the Law $n^{\circ}$ 99/2009, but never applied) and its functions and duties have been temporary assigned to ISPRA (that in fact continue its work as nuclear authority) waiting for a definitive asset of the regulatory organization.

In relation to the key role played by ISPRA in the licensing process and in the supervision activity, and taking also into account the significant effort planned at national level in the fields of spent fuel and radioactive waste management and decommissioning, as well as nuclear safety related activities required by a new regional and international context, also as due to the Fukushima accident, the increase of ISPRA human and financial resources is expected to be undertaken by the Government, even in the context of the current economic difficulties. Such an intervention is essential to be realized in the next future for primarily coping with a process of retirement that already led in the last years to lose a significant number of senior experts, so to ensure the preservation of competencies as well as an adequate coverage of all the regulatory issues relevant for the safe management of radioactive waste and decommissioning and the fulfilment of the increased regional and international obligations on nuclear safety and radiation protection matter. As a measure complementing the expected increase of human resources, ISPRA has in place the development of a KM project based on the IAEA model.

\subsection{Independence of the regulatory function}

The national nuclear Implementer involved in the decommissioning and in the spent fuel and radioactive waste management is SOGIN S.p.A., whose sole shareholder is the Ministry of Economy and Finance, while the strategic and operational policies are given by the Ministry of Economic Development. 
As previously said, licences are granted by the Ministry of Economic Development on the basis of the independent technical advice of ISPRA. ISPRA performs its regulatory functions in a fully independent and autonomous manner. ISPRA is, in fact, a Governmental Agency reporting to the Ministry of Environment, Land and Sea.

Moreover, any approval of specific safety related technical designs and operations are performed by ISPRA, which may establish technical specifications.

As already said, ISPRA is also entitled to issue technical guides on specific aspects related to the regulatory process.

\subsection{Assessment of Compliance}

On the bases of what is reported in this section it may be concluded that Italy has adequate provisions to fulfil its obligations under Art. 8 of the Convention related to independence of the regulatory body.

With regard to financial and human resources assigned to the Regulatory Body, there is confidence that appropriate actions will be undertaken by the Government to overcome the reported difficulties in the context of involved Institutions reorganization. 
Article 9. Responsibility of the licence holder

Each Contracting Party shall ensure that prime responsibility for the

safety of a nuclear installation rests with the holder of the relevant

licence and shall take the appropriate steps to ensure that each such licence holder meets its responsibility.

\subsection{Responsibility of the licence holder}

According to the Law no. 1860/1962 and the Presidential Decree no. 519/1975, the primary responsibility for safety is assigned to the operating organisation. This is confirmed in art. 1 of the Legislative Decree n. 185/2011 with which EU Directive on nuclear safety has been transposed into national legislation.

Therefore the operating organisation is responsible of all the activities having direct influence on safety performed during design, construction, commissioning, operation as well as of all the activities performed during decommissioning and management of spent fuel and radioactive waste.

The regulatory system in place also ensures that appropriate supervision activity is exploited by ISPRA to verify that the licensee holder properly meets its responsibility.

\subsection{Ensuring that the license holder meets its responsibility for safety}

The system of controls provided for in the Italian rules uses four tools:

1. the analysis of the safety reports and other relevant documents, the analysis on the results of tests and measurements, the performance of additional or repeated tests;

2. the inspection system, in order to verify compliance with applicable rules and constraints at all stages from design to operation of facilities as well as during the phases of decommissioning and during all stages of the management of the spent fuel and radioactive waste;

3. the performance of periodic audits to the Applicant and to the Licensee for the purpose of verifying, inter alia, that Licensee maintains the capability in terms of staffing and competences adequate to completely undertake the activities during the lifetime of the facility from siting to decommissioning. Periodic audits to Architect Engineers, Vendors, Manufacturers, and Suppliers in general were also conceived as an indirect tool of control of the Applicant and of the Licensee activities;

4. the sanctions in case of incompliance either with provisions in Law or prescriptions in the licensing acts range from penal to administrative measures. The former can entail deprivation of freedom and fines, the latter consists in suspensions or revocation of the licences in worst cases. The penal sanctions are applied by Courts following reports from 
Inspectors that have Police power in the Italian system. The administrative measures are applied by the Ministry of Economic Development. Before applying the administrative measures, the Ministry can issue an injunction to comply with applicable regulations and technical specifications.

\subsection{Assessment of compliance}

On the basis of what discussed about, it is considered that there are adequate provisions in the Italian legislative system to comply with the obligations of this article of the Convention. 
Article 10. Priority to safety

Each Contracting Party shall take the appropriate steps to ensure

that all organizations engaged in activities directly related to nuclear installations shall establish policies that give due priority to nuclear safety.

With regard to the fulfilment of the requirement under this article of the Convention, it is to be firstly considered that Italy is a Contracting Party that relinquished the operation of its nuclear installations since 1987. In this way, any potential conflict between production and safety has been removed. All the national Organisations have continued to operate with the only aim of maintaining the safety of the shut-down nuclear installations in view of their decommissioning. The principle of priority to safety is clearly addressed in art. 1 , paragraph 2 , letter b of the Legislative Decree n. 185/2011, with which EU Directive on nuclear safety has been transposed into national legislation.

On the implementation side it is addressed by requirements on: Quality Assurance, Operating Organisation rules and Authorisation procedures. Moreover, in the above frames, the licensees are required to issue appropriate documents on their policies on quality, environment and safety, establishing due priority to such topics.

It is anyhow recalled that also at the time of the development of the nuclear programme, the legislative framework and the Italian regulatory practice that have been long in use even before the publication of IAEA Safety Fundamentals, stimulated all the involved national Organisations to be committed to reaching and maintaining the highest priority in safety matters. Example of regulatory tools are:

- Legislative Corpus itself, which imposes a multi-step licensing process;

- General design criteria, requiring, inter alia, the application of the defence in depth principle;

- Regulatory guides, as referred in Annex 3;

- Preliminary, Intermediate and Final Safety Reports;

- Detailed designs;

- Quality Assurance Programmes;

- Safety relevant works Operational Rules;

- Technical Specifications;

- $\quad$ Operating Manual (e.g.: Procedures for normal and emergency condition);

- $\quad$ State exams for Operator Licences and State Certification for Plant Managers;

- Periodic assessment and reporting of performances;

- Inspections. 
Since the inception of the Italian Nuclear Programme, the license holder operates, maintains and modifies the systems of the nuclear power station by assigning the highest priority to the nuclear safety and so keeping the consequential risk to the public as low as reasonably achievable, economic and social considerations being taken into account; this basic principle was implemented even before it was laid down, significantly in art. 2 of Legislative Decree no. 230/1995.

All the national Organisations having competence in the nuclear field are involved in International fora dealing with nuclear safety. Consequently, the latest international achievements have been implemented in Italian applications.

Moreover, various Organisations, dealing with nuclear legislation and/or regulations, such as Ministries, besides ISPRA itself, each give close, independent scrutiny to the documentation submitted by the applicant and to ISPRA safety evaluations. On the operation side, the license holder is required by Law to set up a special Plant Council of Delegates at each nuclear installation site, which has the responsibility to examine all the relevant decisions (e.g.: plant hardware or procedures modifications), in order to identify their safety relevance.

Today, the actual implementation of the priority to safety principle to the Italian nuclear installations regards mainly their safe management and of the associated activities of decommissioning and the spent fuel and radioactive waste management. The safety procedures at the Designer and Operator are today mainly addressed in the activities of modification of existing systems and of construction of new systems and facility for the proper radioactive waste management and performance of decommissioning activities were needed.

\subsection{Assessment of compliance}

Based on information reported above it may be concluded that Italy meets the requirements of this Article of the Convention. 
Article 11. Financial and human resources

1. Each Contracting Party shall take the appropriate steps to ensure that adequate financial resources are available to support the safety of each nuclear installation throughout its life.

2. Each Contracting Party shall take the appropriate steps to ensure that sufficient numbers of qualified staff with appropriate education, training and retraining are available for all safetyrelated activities in or for each nuclear installation, throughout its life.

\subsection{Financial resources}

The National Electricity Company (ENEL S.p.A.) decided to start accumulating decommissioning funds during NPP operation even without a formal obligation. At the time of the premature shut down of these plants however all the necessary decommissioning funds were not available. When in 1999 all the liabilities and assets related to nuclear power plants belonging to ENEL were transferred to the newly established company SOGIN S.p.A (Società Gestione Impianti Nucleari), soon new funding mechanisms were identified to finance the full decommissioning costs. Since January 2000 the financial resources are provided by a levy on the price of the kWh to the consumers in combination with the pre-existing ENEL funds that have been transferred to SOGIN S.p.A. which is responsible for performing decommissioning and waste treatment activities for all Italian nuclear installations. Funding of the fuel cycle facilities in decommissioning has been included in the above mentioned levy.

Every year SOGIN shall submit to the National Authority for the Electricity and Gas an updated report on technical and economic plans for the decommissioning projects. The yearly reports have also to contain an update of the decommissioning plans and of cost estimates. The levy on kWh, paid by the final users, is adjusted every 3 months. In this way, possible additional costs due to changes of strategies and the activities needed for safety reasons, can be endorsed by the National Authority for Electricity and Gas. Efficiency criteria related to the program management and to the progress of activities are taken into account in performing such adjustments. In the third quarter of 2013 the levy has been about $0.36 \%$ of the kWh price and equal to 1.85 Euro/year to the average electrical average consumer.

The main component of the total decommissioning costs is the waste management and, in particular, the waste disposal cost, which strongly depends on the fees that will be required for the disposal in the final repository. The following activities were taken into account in the decommissioning scope: 
- $\quad$ Site care and safe management

- $\quad$ Project management and licensing

- $\quad$ On-site interim storage of spent fuel;

- Structure, systems and components decontamination aiming at maximizing conditional and unconditional recycling, re-use or free release;

- Radioactive waste treatment including volume reduction (e.g. compaction);

- Conditioning and packaging of historical/operational waste, e.g. sludge, ion-exchange resins as well as decommissioning waste;

- Dismantlement of power reactor/fuel cycle facility civil structures;

- Dismantlement of conventional plant buildings, e.g. turbine hall;

- Radioactive waste disposal ;

- Disposal or recycling of non-radioactive waste material;

- Final site surveys;

- De-licensing of the site.

\subsection{Human Resources}

Since the inception of the Italian Nuclear Programme, the licence holder was committed to provide human resources throughout the entire life cycle of the plant in order to ensure a safe operation.

It is important to highlight that the ongoing process of retirement by the experienced staff at several nuclear installations might create difficulties to the national nuclear activities, even if SOGIN, the Implementer of the national decommissioning activities, recently started a recruitment program of young professionals.

Italian Laws state that the operating personnel for the NPP's must follow an appropriate training programme and their capacity to operate in a nuclear installation must be certificated. Qualified positions in the staff of the NPP's are approved by the Regulatory Body together with the Operation Rules. To certificate the operator qualification, many examinations must be passed by each person. The responsible of health physics must be member of the "health physics association" at level 3 (the highest one).

Implementation of additional concepts associated to the SMS will be required by ISPRA through the updating of pertinent Technical Guides.

Today, staff qualification requirements for decommissioning and radioactive waste and spent fuel activities are the main focus of human resources management. Technical and operating staff undertake training regarding technical and legal issues, according to the specific policy of SOGIN S.P.A. established at corporate level. Moreover, staff qualification for the performance of any safety-related activity is among the relevant aspects that are assessed during the 
licensing process. In nuclear installations and facilities, only licensed personnel can operate. In such installation the Operation Rules, required by the Italian law, establishes requirements about the organization and the roles of the technical and operating staff, to ensure a safe management of the installation (even regarding the activities related to waste management and dismantling operations) in ordinary and emergency conditions.

Among the main objectives of the mentioned safety strategic project by the Implementer SOGIN, many internal activities related to human resources training were carried out by the SOGIN "Radiological Protection, Environment and Nuclear Safety School", established in February 2008.

The School was specifically created to ensure the diffusion, development and consolidation of the radioprotection and nuclear safety culture. The fundamental goal was and is to promote shared and adequate behaviours among the personnel operating in the decommissioning activities and, by doing so, to contribute to the enhancement of the safety standards.

In April 2010 the Radiological Protection and Nuclear Safety School was awarded the ISO 9001:2008 certification by the DNV (Det Norske Veritas) for its teaching activities in the field of radioprotection and nuclear safety.

Main courses at the school are: radiation protection for qualified personnel radiation protection for new employees, general nuclear safety from design to testing, management of radioactive materials and radiological characterization of the plant, assessment of environmental impact, internal and external dosimetry, nuclear safety culture, Italian radiation protection regulations.

In 2012 about $60 \%$ of SOGIN employees participated to one or more courses.A tailored program of classes on radioprotection and nuclear safety is also in place for subcontractors' workers operating on safety related systems and components and/or in radiologically controlled areas.

\subsection{Assessment of compliance}

Based on information reported above it may be concluded that the Italian licensee is going to overcome the lack of resources outlined in the previous Report and is actively operating in the area of training/retraining, and then Italy meets the requirements of this Article of the Convention. 
Article 12. Human factors

Each Contracting Party shall take the appropriate steps to ensure

that the capabilities and limitations of human performance are

taken into account throughout the life of a nuclear installation.

\subsection{Methods to prevent, detect and correct human errors}

The important role of human performance in all phases of the life of a nuclear installation from design and operation until shut-down and decommissioning, has always been focused as an important safety concern. Adapted to the scope of the current national nuclear programme regarding the management of shut-down plants and the associated activities of decommissioning and spent fuel and radioactive management, these aspects include:

\section{Safety relevant work Organization Rules}

Operation Rules, on-site Organisation Chart, Roles and Responsibilities as summarised under the managerial and organisational issues in the following section.

\section{Procedures development}

The procedures development, in particular for the emergency situations, is performed by taking into the human factors issue. Procedures are verified with respect to technical accuracy, written correctness and usability.

\section{Operator Training}

SOGIN technical and operating staff undertakes training regarding technical and legal issues as dealt with in the previous paragraph on the human resources.

\section{Good understanding and clarity of Technical Specifications (TS)}

While dedicating a particular care in writing the TS, a great emphasis is given to human factors principle in order to ensure a clear understanding to TS requirements. From the human factors point of view, particular attention is devoted to exclude conflicting interpretation of TS requirements and to provide the associated technical bases.

\subsection{Managerial and organizational issues}

According to the Italian law, the licensee must provide the Regulatory Body with organisational rules related to safety relevant works to be carried out in the installations. This document has to specify the organisation and functions of the staff under both normal and abnormal conditions, including the physical and medical surveillance of radiation protection at all modes of operation and has to be approved by the Regulatory Body. 
The Italian Regulatory Body has defined a Technical Guide on the contents of the safety relevant work Organisation Rules with several specific criteria for the approval of the Operator's document.

Safety of a nuclear installation, also in decommissioning phase, requires, from the human factors point of view, the maximum order in the methods of operation. This in order to avoid a state, also partial, of "organisational confusion", due to significant lacks in the design of the human system or in the supervisory system, that are the frequent root cause of many accidents. Criteria of the Italian Regulatory Body require that the activities, relevant for the safety, are clearly defined, and properly assigned. These activities must also be executed according to predetermined and written procedures, carefully recorded, regularly supervised, and the whole system readily corrected when necessary.

\subsection{Safety culture and Safety Management System (SMS) and associated surveillance} rules

Methods of assessing safety culture which comply with proved international practices (e.g. SCART technique) are being implemented.

Safety culture is stimulated and improved by a complex combination of education, training, behaviours and attitudes, Company commitments, etc.. Therefore, a consolidated and distinctive set of Key Performance Indicators (KPI) has not yet been consolidated at international level. In addition, a decommissioning process involves some specific challenges to manage the transition phases and to maintain the safety culture of the personnel and that of the Contractors' personnel.

SOGIN, together with a number of other initiatives, has still in experimental phase a set of KPI that are going to be part of the self-assessment program on safety culture and will be used to decide any necessary corrective action. Such KPI were derived from the available information in the literature or from bilateral contacts with other Companies and have been adapted to the current SOGIN situation, practices and priorities.

These KPI include:

- Number of training days on nuclear safety related subjects;

- Number of potential safety related issues identified by personnel and formally or informally reported;

- Number of Technical Specification violations;

- Number of identified Company procedure violations;

- Number of visits of Top Managers on the sites specifically on safety related issues;

- Number of internal and external communications by the Top managers where safety is clearly indicated as a Company priority; 
- Number of meeting-days on safety related operational experience review;

- Number of training hours for Contractor personnel involved in activities in controlled areas and/or on safety related equipment.

SMS is planned in relation to the activities having priority with regard to the current national nuclear programme (decommissioning and radioactive waste management) and building on the existing organization requirements for the Licensee. From a regulatory point of view the consideration of SMS requirements will be done in the context of the national action plan to update technical guides as follow up of the WENRA harmonization process. It must however be underlined that specific provisions already exist in the legislative system, which require that the on-site organization of the Licensee has to be approved by the Regulatory Body. Such an approval is granted on the basis of a specific document (i.e. Operating Organisation rules) which has to clearly define all roles and competences of the on-site organization of the Licensee having relevance to safety. The submission and approval of this document is required in any phase of the NPP life, including decommissioning. In addition to that for each site a QA programme is requested. The basis of the SMS are going to be IAEA and WENRA Reference Level. Implementation of many concepts of SMS is binding, being requested by legislative provisions (see Operating Organisation rules).

In the years 2007-2009 the Operating Organization Rules of the four NPP's have been updated and approved by the Regulatory Body. They envisage an organization tailored to ensure an high level of safety and radiation protection during decommissioning activities. Key feature of the new operating Rules are:

- a clear allocation of responsibilities at management and operational level;

- a proper exploitation of interfaces among safe management of the installation and performance of decommissioning activities;

- qualification of personnel;

- $\quad$ strategic plan for ensuring qualified human resources;

- management of contractors activities.

New QA programmes have been submitted, based on Management System Manual which already takes into account the most recent IAEA Requirements as reference.

\subsection{Role of the Regulatory Body and of the Operator regarding Human Performances issues}

The Italian Regulatory Body, in the frame of its general duties, is also responsible for the controls on the training system and conducts the examinations on SOGIN operators working in nuclear installations. 
ISPRA established criteria for a self-corrective quality system, that has to be effective at various levels along the vertical axis of the operating organisation.

\section{Plant Management Level}

The institution of an Advisory Council on Safety (also called "Plant Council of Delegates") is required on each plant. This Council is formed by plant technicians supervising the most relevant activities (e.g.: operation, maintenance, radiation protection) supporting the Plant Superintendent with the following consultative functions, according to the Italian Law:

a) to review any proposed modification to the plant or to part of it and to express evaluations and advice on safety matters;

b) to review any proposed modification to the operating procedures of the plant and to express evaluations and advice on safety matters;

c) to review programmes of trials, tests, and other special activities to be carried out on the plant and to express evaluations and advice on safety matters;

d) to review periodically the overall operation of the plant, and to express opinion and possible recommendations regarding safety and protection;

e) to lay down the internal emergency drill for the plant and arrange for any necessary modification in consultation with the Provincial Fire Service Headquarters;

f) to assist the emergency director (person qualified by state examination to the "Direction" of nuclear plant in normal and emergency conditions, in "on call availability shift") or the plant superintendent in the adoption of the measures which may be necessary to deal with any unusual or abnormal condition which may constitute a danger for persons or things.

Also the recent safety strategic project to be performed by the Implementer SOGIN for responding to the ISPRA request, will ensure that the capabilities and limitations of human performance are taken into account with special regard to decommissioning activities to be performed in the next future.

\subsection{Assessment of compliance}

Based on information reported above it may be concluded that Italy meets the requirements of this Article of the Convention. 
Section C. Compliance with articles 4 to 19 
Article 13. Quality assurance

Each Contracting Party shall take the appropriate steps to ensure

that quality assurance programmes are established and

implemented with a view to providing confidence that specified

requirements for all activities important to nuclear safety are

satisfied throughout the life of a nuclear installation.

Although the legislative system does not contain specific provisions regarding quality assurance in nuclear installations, QA requirements are detailed in specific Technical Guides issued by the Regulatory Authority in the middle of 70's and at the beginning of 80's, in the frame of a more general programme of development of technical guides to support the regulation of installations of the national nuclear programme. Technical guides are normally used as key references regulatory tools during the Licensing process. They do not have a mandatory character but, in case of non compliance, the licensee is requested to demonstrate that the safety case fulfil alternative equivalent requirements. On the bases of the requirements established in the technical guides, licensees developed proper QA General programmes for conduct of operation and/or Quality Procedures Guidelines/Instructions under the supervision of the Regulatory Body. Reference to a list of the major Technical Guides developed by the Italian Regulatory Body in matter of Quality Assurance is reported in Annex 3.

For installations which have submitted the request of licence for the decommissioning plan, conditions attached to the licence will establish the requirements for the licensee to perform the decommissioning activities according to a QA programme to be submitted and approved by the Regulatory Body.

With regard to new facilities connected to the treatment and the storage of radioactive waste to be realized as preliminary activities for decommissioning, QA requirements (as defined in the Technical Guide $n^{\circ} 4$ related to the standard content of applications for detailed design of relevant parts of nuclear installations) are applied. In particular, an adequate demonstration with regard to quality assurance related aspects is requested to be provided by the licensee in the specific safety case, developed according to the Technical Guide $n^{\circ} 1$, submitted to support the authorization.

With reference to the current implementation level, it is to be mentioned that the QA system of SOGIN S.p.A., as the main national licensee involved in the management of spent fuel and radioactive waste, is documented through two levels of documentation applicable for all projects:

- Management System Manual related to the main organization; 
- Quality Assurance Programme related to the dismantling activities and operation of each site;

- Quality procedures/Guidelines Instructions and a third level of specific documentation for each project, related to Job Order documents.

Also for the establishment and the implementation of Q.A. safety requirements, the process put in place in Italy is a development process similar to the other safety requirements.

\subsection{Regulatory control}

In addition to the issuing of the above listed Technical Guides, the regulatory control during the licensing process is based on the analysis and review of QA Programmes submitted by the Applicant.

An additional primary tool of Regulatory Control is the possibility to perform periodic audits to the Applicant and to the Licensee.

\subsection{Assessment of compliance}

Based on information reported above it may be concluded that Italy meets the requirements of this Article of the Convention. 
Article 14. Assessment and verification of safety

Each Contracting Party shall take the appropriate steps to ensure that:

i. comprehensive and systematic safety assessments are carried out before the construction and commissioning of a nuclear installation and throughout its life. Such assessments shall be well documented, subsequently updated in the light of operating experience and significant new safety information, and reviewed under the authority of the regulatory body;

ii. verification by analysis, surveillance, testing and inspection is carried out to ensure that the physical state and the operation of a nuclear installation continue to be in accordance with its design, applicable national safety requirements, and operational limits and conditions.

It has to be said that in relation to the decommissioning state of all NPPs, the preservation of high level safety conditions remains one of the key objectives of the regulatory oversight activity. In addition to that special attention is devoted by the regulatory authority to verify that the licensee performs in due time waste conditioning, final spent fuel management and dismantling activities relevant to improve safety, perform any activity in compliance with safety and radiation protection requirements and produces adequately conditioned radioactive wastes.

It has to be highlighted that following their definitive shutdown, preservation of high level safety conditions primarily founded on the maintaining of rules established for operation, even though progressively adapted as required by the new plants' state. This means the maintenance of technical specifications commensurate to the plant state, with a conservative attitude in maintaining consolidated practices even when they might be made lighter (Operators' license and Operating Manual).

As previously referred, the decommissioning license has been granted for Trino and Garigliano NPP while the authorisation process for Caorso and Latina NPPs will follow in 2013-14. In particular, due to said uncertainties on the availability of a national radioactive waste repository, ISPRA, in the framework of the authorization process, has clearly underlined (e.g.: Garigliano case) the need for the identification, with the associated feasibility demonstration, of a clear strategy concerning the management and safe storage of radioactive wastes already existing and estimated to be generated during decommissioning activities. Among the alternative solutions to the current unavailability of a national facility for radioactive waste management, the construction of interim storage facilities for radioactive waste on site or the shift to a safe 
enclosure state of the remaining structures (e.g. as in the case of the Latina NPP core graphite structure) have been considered.

On that basis, being the programmes of decommissioning structured in three main stages (Annex 5) primarily addressed to safety priority interventions and preliminary operations, dismantlement of the nuclear island, final radiological survey and site release, the respective authorizations are granted as:

- a general permit to pursue the overall decommissioning in the frame of a specific set of criteria and constraints;

- $\quad$ specific permits for well defined short term activities;

- a request to present specific decommissioning projects for the subsequent relevant activities, for which a detailed definition is not yet available.

In this respect, the safety case documentation submitted for the decommissioning is addressed to define the selected decommissioning strategy, to provide a description of the plant state, the radiological characterization of the plant as well as the safety assessment in relation to abnormal events or accidents, the demonstration of technical feasibility of the proposed operations in compliance with nuclear safety and radiation protection requirements are presented. This is considered to be at the appropriate level of detail for a licensing process involving Authorities such as Ministries and Local Administrations, in accordance with the applicable articles of the Legislative Decree no. 230/95 and taking into account the long lasting time necessary for the development of decommissioning operations.

Taking that into account the decommissioning license establishes:

- a set of conditions and limits "specifications" either at management and technical level which will regulate the performance of the decommissioning operations up to their completion;

- a number of safety relevant decommissioning projects to be submitted to the approval of the regulatory authority.

In particular, a decommissioning project can be articulated in a "detailed project", in the case of new installations necessary for the implementation of the authorized decommissioning strategy are concerned (e.g. new RW storage facilities, RW on site treatment facilities, etc.). In case dismantling activities are concerned specific "operation plans" are requested to be submitted to the Regulator's approval.

Licensing documentation related to detailed projects and operational plans has to contain specific sections on safety assessment of pertaining decommissioning activities .

Taking also into account that the planned decommissioning operations will have a long lasting time of development, it is envisaged the need of defining those safety related activities whose detailed designs, with associated safety analysis, have to be submitted to ISPRA for approval. In fact, for instance, the acceptability of design requirements for facilities to be built (i.e. storage 
facilities and systems), as well as of dismantling techniques and methods in line with the international state of the art, deserves adequate in depth review.

In this regard, on the basis of the lessons learned from Fukushima, it is mentioned that for the new interim waste storage facilities under construction at the NPPs sites a verification of existing margins against seismic events and an increased protection against flooding are requested in the licensing process. Such requirements will be also considered for the authorization process regarding the national repository siting and construction.

A meaningful example refers to the complexity of the issue of the unconditional release of materials resulting from decommissioning; it is recognised that this activity must be duly prepared, well in advance, both from regulatory and licensee side. Appropriate clearance levels are identified and specific radiological characterization plans and procedures for radiometric verifications established. Qualified measuring laboratories have to be selected or set up in some cases and on site measuring capabilities of due size have to be timely prepared.

Given the specific situation, it is also considered of outmost importance to maintain large margins for on site waste storage capacity. In fact, the routine waste production for long periods, the possible unexpected needs of interventions on dangerous aged structures, the possible interventions on the wastes themselves (re-treatment/conditioning) call for the availability of large spare areas.

With the aim to provide an updating on the measures in place ensuring the maintenance of the safety and radiation protection provisions on all installations, specific information are reported in the Annex 1.

\subsection{Assessment of compliance}

Based on information reported above it may be concluded that Italy meets the requirements of this Article of the Convention. 
Article 15. Radiation protection

Each Contracting Party shall take the appropriate steps to ensure that in all operational states the radiation exposure to the workers and the public caused by a nuclear installation shall be kept as low as reasonably achievable and that no individual shall be exposed to radiation doses which exceed prescribed national dose limits.

\subsection{Laws and Regulations}

The main Law that regulates radiation protection matters is the Legislative Decree no. 230/1995 and its modifications, as previously described in Article 7.1.

It must be said beforehand that the text of Legislative Decree no. 230/1995 was written in 1990s in order to enact the transposition of six EURATOM directives previously issued by the European Union, of which Italy is a member, and to profit from the wealth of past operational experience in radiation protection. During the preparation of Legislative Decree no. 230/1995, the International Commission for Radiological Protection (ICRP) issued its new recommendations in Publication no. 60 of 1991, of which one of the most important features was new dose limits for workers and public. The Italian Authorities decided to enact the new dose limits recommended by ICRP Publication no. 60 even though the European Union had not yet issued at the time a directive to that effect.

Legislative Decree no. 230/1995 was modified by Legislative Decrees no. 241/2000 and no. 257/2001, in order to implement the Euratom Directive 96/29. The Legislative Decree regulates every aspect of the radiation protection in nuclear installations and in non nuclear installations or facilities (accelerators, irradiators, hospitals and other medical uses of radiation sources); it contains thirteen Technical Annexes. A series of Governmental and Ministerial Decrees have also been issued in implementation of the Legislative Decree no. 230/1995.

The Law established the ALARA principle as required by Euratom Directives and fixes dose limits for workers and public even more restrictive than those required by such a Directive.

A detailed description of the Italian radiation protection system is provided in the Annex 4.

\subsection{Assessment of compliance}

Based on information reported above it may be concluded that Italy meets the requirements of this Article of the Convention. 
Article 16. Emergency preparedness

i. Each Contracting Party shall take the appropriate steps to ensure that there are on-site and off-site emergency plans that are routinely tested for nuclear installations and cover the activities to be carried out in the event of an emergency.

For any new nuclear installation, such plans shall be prepared and tested before it commences operation above a low power level agreed by the regulatory body.

ii. Each Contracting Party shall take the appropriate steps to ensure that, insofar as they are likely to be affected by a radiological emergency, its own population and the competent authorities of the States in the vicinity of the nuclear installation are provided with appropriate information for emergency planning and response.

iii. Contracting Parties which do not have a nuclear installation on their territory, insofar as they are likely to be affected in the event of a radiological emergency at a nuclear installation in the vicinity, shall take the appropriate steps for the preparation and testing of emergency plans for their territory that cover the activities to be carried out in the event of such an emergency.

\subsection{On-site and off-site emergency plans}

Emergency planning at nuclear installations is regulated in Italy by the provisions reported in Articles 115 to 135 of the Legislative Decree $n^{\circ} 230 / 1995$ and subsequent amendments. In addition, the general legislation governing emergency preparedness and response provisions in all cases of accidental events and disasters, as reported in the Act $n^{\circ} 225 / 1992$ and subsequent amendments, is applicable.

With regard to on-site emergency planning above provisions are complemented with those reported in Articles 47 and 49 of the Legislative Decree $n^{\circ} 230 / 1995$ respectively related to the Manual for the Conduct of Plant Operation and to the role of the Plant safety Committee which include, among other duties, the preparation of the on-site emergency plan.

Technical Specifications attached to the license regulate the performance of periodic emergency drills. As a normal practice these drills are also attended by representatives of the Regulatory Authority. 
As far as off-site emergency preparedness response concerns its organization differs depending on extension and type of the consequences of the postulated events (namely events which could affect a local area or a larger part of the national territory).

If the potential consequences of postulated reference events result to be manageable at local level, the off-site emergency plan is prepared under the authority of the Prefect of the province where the installation is located, as stated in Articles 118, 119 and 120 of the Legislative Decree $n^{\circ} 230 / 1995$. According to article 117 of the same legislative decree, the technical basis for the plan are established by the Licensee and revised by the Regulatory Authority. The plan is prepared taking into account the provisions reported in the Law $n^{\circ} 225 / 1992$.

At present, all nuclear installations have in place an off-site emergency plan. Emergency preparedness provisions are therefore sized to ensure a level of protection to the public and the environment beyond the current level of risk of the installation. In other cases, a re-evaluation of the technical bases has been performed and the plan consequently updated.

An updating of the emergency plan is performed following the authorization of the decommissioning plan, and in any case, following the removal of spent fuel from the site.

It is to be mentioned also that specific emergency plans are prepared for the transport abroad of spent fuel for reprocessing according to a specific Government regulation (art. 125 of Legislative Decree 230/1995).

Cases where postulated reference events could lead to radiological consequences investing larger parts of the national territory, are regulated by specific provisions of the Legislative Decree $n^{\circ} 230 / 1995$ (article 121) related to the National Plan on Radiological Emergencies, as referred in the following point.

\subsection{National Plan against Radiological Emergency}

Provisions of Section 121 of the Legislative Decree $n^{\circ}$ 230/1995 require the preparation of a general National Plan of Protective Measures for Radiological Emergencies under the authority of the Department of Civil Protection. Such a plan is aimed at protecting general public and environment in case of accidents occurring at an Italian installation or at an installation located in a neighbouring country, as well as of emergency situations at undetermined location in the territory.

The current edition of the National Plan for nuclear emergency was approved in March 2010 by the Italian Government. The Plan was prepared by the Department of the Civil Protection of the Council of Ministers and represents a revision of the previous 1997 edition.

This revision of the National Plan results from the following technical and operational factors: 
- the review of accident scenarios taken as reference for planning interventions in case of accidents at NPPs across the border, referring to situations more severe than those previously considered, in order to identify areas most at risk in case of trans-boundary releases;

- the updating of dose intervention levels as required by the current regulations;

- the taking into account the current legislation on the role of local authorities (Regional Administration and Prefectures) in emergency planning and some recent provisions on civil protection;

- the updating of the framework of the central technical facilities and the taking into account the establishment of the radiological alarm automatic networks and the reorganization of framework of the regional environmental laboratories that are part of the national surveillance network of the environmental radioactivity.

\subsubsection{Reference accident scenario and consequences assessment}

The national plan adopted in 1997 considered severe accidents, involving core meltdown, but assuming a capacity of the containment system to limit the release to the environment. For the updating of the Plan, the Department of Civil Protection asked the ISPRA (responsible of the preparation of the study) to assess the new technical basis extending the response capabilities envisaged by the Plan.

The technical bases of the Plan have been assessed taking into consideration an envelope of the accident scenarios used as reference for emergency planning in the countries with NPPs close to the Italian border. Particularly, scenarios characterized by core damage and loss of containment was considered. With regard to scenarios of this nature it is still considered reasonable to assume a partially effective capacity of mitigation actions existing on site. The scenarios identified are for NPPs up to 1500 MWe.

It is therefore believed that these provisions properly bound conditions potentially related to events occurring to radioactive waste and spent fuel installations in the vicinity of the national territory.

Scenarios include particularly severe accident events, with a very low probability, during which, despite several failures of the safety systems and core damage, it is still possible to assume that:

- for events that originate within the plant, abatement systems and containment, although partially degraded, can continue to provide a barrier which would limit the release to the environment;

- in the event of external origin producing the loss of primary containment system, recovery and mitigation actions could arrest the process of core melting or lead to a partial removal of the radioactive particulate; 
The releases calculated in these conditions, are about $10 \%$ of the total inventory.

Assuming the above envelope source term, simulation of the atmospheric dispersion was carried out starting from the closest foreign NPP to the Italian border, selected also considering other relevant factors such as orographic configuration and prevailing winds.

The simulation was performed by using the long-range atmospheric dispersion model running into the ARIES System (Accidental Release Impact Evaluation System) which is operative at the Nuclear Emergency Centre of ISPRA. ARIES was run assuming particularly unfavourable atmospheric conditions occurred over several years.

Dose assessment results suggest to consider in the Plan the adoption of sheltering and stable iodine administration as possible protective measures in some areas of regions located close to the border.. Moreover, the expected ground contamination requires the implementation of a radiological monitoring programme to be extended on large areas of the country, aimed at controlling environmental matrices and the food chain for providing the necessary technical basis for any decisions about food production and consumption restrictive measures.

\subsubsection{Operational level of the emergency response}

After the receiving of the notification of a nuclear accident, two operational level are defined by the Plan:

- a Warning Level in case of an accident at a nuclear plant within $200 \mathrm{~km}$ from the Italian border, which entails the following main activities:

- the acquisition of further information about the event and its evolution;

- activation of the radiological monitoring capabilities at national and local level;

- public information, and

- an Alert Level, as the evolution of the previous scenario with involvement of the national territory and possible activation of the protective measures. After the declaration of the Alert (by the National Department of the Civil Protection) the activities envisaged by the Plan are aimed at the following objectives:

- event monitoring, evaluation of the radiological consequences and full activation of the national and regional radiological monitoring network;

- activation of the structures of the national service of the Civil Protection;

- definition and implementation of the protective measures (sheltering, iodine prophylaxis);

- public information.

Regarding the administration of stable iodine tablets, its implementation follows an assessment of the emergency situation and it is established by mutual agreement between national and regional Authorities. The regional Administrations have the responsibility to prepare and manage the stockpiles of stable iodine tablets and to define procedures for the distribution to 
the public. Planning activities aimed at establishing the storage and administration strategies are ongoing in the Regions most exposed to the consequences of a nuclear accident supposed to occur in neighbouring countries (Northern regions of Italy). Furthermore, there is a national stockpile that can be used to cope with specific situations: for example, peaks of the presence of tourists.

\subsubsection{Emergency organization}

On the basis of the identified accidental scenarios and the technical competence, the national Plan establishes the ruling structures (competent Authorities) as well as the technical and the operative bodies, both at national and at local levels.

The ruling structure is the Prime Minister (or a delegate) with the support of the Operative Committee of Civil Protection, consisting of representatives from all related national administrative bodies (Department of Civil Protection, Ministry of Interior, Ministry of Health, Ministry of Defence and others).

In case of a national emergency the technical body is the Centre for Data Elaboration and Evaluation (CEVaD), as stated at art. 123 of Legislative Decree $n^{\circ} 230 / 1995$, which includes representatives of ISPRA (as coordinator), the National Institute of Health (ISS), the National Workers' Compensation Authority (INAIL), the National Corp of Fire Brigades, the National Meteorological Service of the Air Force and representatives of regional laboratories for the environmental radioactivity surveillance. ISPRA provides also technical and logistic support for CEVaD.

The Centre is entitled to follow the evolution of the radiological consequences of the event in order to provide the Operative Committee of the Civil Protection with the proper recommendations in relation to the protective actions to be undertaken where required.

The Centre operates according to established procedures contained in the "Operational manual for the dose evaluation and the environmental monitoring in case of a nuclear and radiological emergencies" (revision 2010). The manual describes the tasks of the Committee and the procedures used for dose assessments from different exposure pathways during a nuclear or radiological emergency. Dosimetric intervention level and derived operational intervention levels for protective measures implementation are reported. The most significant radiometric data in the management of an emergency are indicated providing the operational guides for the sampling and measurement activities of environmental and food matrices.

The Centre also makes use of important technical support features which are operative at the ISPRA Nuclear Emergency Centre, such as the nationwide automatic networks for the environmental radiological monitoring of the gamma dose rate and the airborne radioactive particulate which participate in the national early warning system, and the aforementioned 
ARIES computational system with models able to estimate the medium and long range dispersion of radioactive contaminants released into the atmosphere from any installation located in Europe.

The monitoring data from the aforementioned gamma dose early warning network are made available, both in routine and in emergency condition, to the European Radiological Data Exchange Platform, EURDEP, under provisions set out by a Memorandum of Understanding between the European Union and ISPRA which acts as National EURDEP Data Provider for Italy. Furthermore, the nationwide network has been integrated with the local regional monitoring network, managed by the regional agencies for the environmental protection, to better monitor the areas of the country closer to the abroad NPP.

Italian organisations involved in the implementation of the national plan, regularly participate in emergency exercises organized at international level by EU (ECURIE), IAEA (EMERCON) and OECD/NEA (INEX). Moreover, within the framework of bilateral agreements, the participation is extended to the national exercises promoted and played by the neighbouring countries.

National exercises have been also undertaken in the past and a new exercises series aimed at testing the updated national plan has to be organised under the coordination of the Department of Civil Protection.

It is finally to be mentioned that, at international level, Italy has ratified the Convention on Early Notification of a Nuclear Accident (1986) and the Convention on Assistance in the Case of a Nuclear Accident or Radiological Emergency (1987). Italy also established proper provisions to fulfil the requirements of European Union Council Decision $n^{\circ}$ 87/600/Euratom regarding the urgent exchange of information in case of radiological emergency.

\subsection{Bilateral Cooperation}

A plan to establish bilateral cooperation on nuclear and radiological emergencies with neighboring countries having NPPs was launched on late 2009 and concluded in 2010-11 as reported in the following paragraphs.

The implementation activity of such a cooperation expedited in the aftermath of the Fukushima Daiichi NPP accident.

\subsubsection{Agreement with Switzerland}

An Agreement between the Swiss Federal Council and the Government of the Italian Republic on the rapid exchange of information in case of nuclear accidents was signed on 15th December 1989 and entered into force on 26th February 1990. On this basis regular communication drills take place between the respective national contact points.

Hereinafter, some representative clauses of this Agreement are reported. 
Parties are committed to notify each other the respective national competent Authority to coordinate the emergency and the respective contact point authorized to receive information Parties are committed to notify each other immediately about emergency situations that could have radiological consequences, as well as abnormal levels of radioactivity on their territory, which have arisen as a result of any kind of activity.

The information exchange system has to ensure the receipt and transmission on $\mathrm{H} 24$ and that the operating procedures are periodically tested.

Information about the emergency has to be promptly forwarded by the interested Party and to cover date, time and place of the event, its nature and the measures planned or taken on own territory and any further available information relevant to minimize the radiological consequences on the population of the other Party.

More in detail, the information has to be constantly integrated by all other information available so to allow the assessment of the risks associated and in particular: presumed or established cause of the event and the characteristics of the potential release (nature, physical and chemical form and, to the extent possible, the quantity of the radioactive release); meteorological and hydrological data for prognosis evaluation and data from radiological measurement of environmental samples (air, water, soil), of animals, of foodstuffs, of feed and drinking water.

In case of an emergency state, the Agreement provides also for sending an own correspondent to the other Party.

In order to complement the above State level Agreement, a cooperation Arrangement between the Swiss Federal Nuclear Safety Inspectorate (ENSI) and ISPRA on nuclear safety matters was concluded on June 2011.

On November 2012 an Italian-Swiss Commission for the cooperation on emergency preparedness and response and on matter of nuclear safety was established with the task to coordinate the overall cooperation activity.

In this context also the national emergency Organizations (Civil Protection Department of the Presidency of the Council of Ministers for Italy and the National Emergency Operations Centre of the Federal Office for Civil Protection of Swiss Confederation) attend the regular meetings scheduled under the cooperation Agreement.

\subsubsection{Arrangement between ASN (France) and ISPRA}

A cooperation Arrangement between the French and Italian nuclear safety Authorities (ASN and ISPRA) was signed on April 2010. The Arrangement is based on the early exchange of 
information in the event of a radiological emergency and on the co-operation in the field of the nuclear safety.

In case of an event that could endanger the population of the other country, the Party is committed to notify to the other one the event, its nature, the time and location of its occurrence and any further available information relevant to minimize the radiological consequences on the population of the other country.

The Agreement provides for the setting up a joint expert group with the task to provide a common identification of the set of specific data to be transmitted both at onset of the event and during the evolution of the accident, and the transmission method.

The points of contact of the Parties are to be available on $24 \mathrm{~h} / 7 \mathrm{~d}$ bases and are to be put periodically under test.

Concerning the co-operation on nuclear safety matters, the Arrangement provides for the information exchange and cooperation in many areas of the nuclear safety regulatory matters, for example:

- legislation, regulation, safety guides and technical criteria regarding siting, design, construction, operation, decommissioning and waste management;

- licensing, inspection and enforcement procedures;

- $\quad$ regulatory procedure and assessment methodologies related to nuclear safety, radiation protection, quality assurance, emergency planning, environmental impact evaluation, waste management and transportation;

- $\quad$ major public information activities;

- $\quad$ information concerning research and development programs.

\subsubsection{Arrangement between SNSA (Slovenia) and ISPRA}

A cooperation Arrangement between ISPRA and the Nuclear Safety Administration (SNSA) of the Republic of Slovenia for the early exchange of information in the event of a radiological emergency and co-operation in nuclear safety matters is in place since May 2010.Scope and terms of this Arrangement between SNSA and ISPRA are similar to those above reported for the Arrangement concluded between ASN and ISPRA. 


\subsection{Lessons Learned from the response to Fukushima nuclear emergency}

As described above, the national nuclear emergency plan currently in force assumes as reference events for its activation the occurrence of a severe accident in a nuclear installation close to the Italian border. The plan activation level depends on the involvement of the national territory by the radioactive release and on the need to adopt protective measure in order to protect people living in the regions affected or potentially affected by the accident consequences.

No provision or procedure is foreseen in the national plan in order to respond to nuclear emergency which should occur far away from the national borders.

As a matter of fact, following the initial international emergency notification reporting the Japanese nuclear emergency, the Emergency Response Centre of the National Department of the Civil Protection of the Presidency of the Council of Ministers and afterwards the Operative Committee of Civil Protection (where the ministries and all relevant national organization are represented) responsible of the management of the nuclear emergency response at national level, decided not to activate the national plan.

Therefore, the national response to the Japanese nuclear emergency involved the following organizations, each according to their institutional responsibilities.

- The Ministry of the Foreign Affairs activated a crisis cell supporting the Italian Embassy in Tokyo to assist the Italian citizens both for their stay in Japan or return to Italy giving them assistance for the re-entry flights.

- The Ministry of Health provided information and issued provisions about the health risk correlated to the radioactivity released during the accident. Specifically, in the first phase of the event, advices have been provided with reference to the re-entry of citizens from Japan (for example, the matter of the screening on passengers, crew, baggage and airplane). Moreover, provision for the improvement of the control on imported food and feeding products was issued since March 16th, before the European Commission issued specific recommendations. The Ministry coordinated the monitoring activities on food and feed products coming from Japan and on the fish and fishery products from areas of Pacific Ocean surrounding Japan, reporting the results to the Commission. Moreover, following the specific recommendation from EC, the Ministry coordinated the radiological checks at the principal Italian ports on ship and ship container arriving from Japan and containing non-food products.

- The National Department of Civil Protection of the Presidency of the Council of Ministers gave its qualified organizational support in coordinating two missions (March 15th and 28th) of expert team sent in Japan with the objective to support the Italian Embassy and Italian citizens in Japan. Moreover, the Department followed the evolution of the event as national competent 
Authority for abroad emergencies under the international Convention on early notification and assistance and EC emergency communication system (Ecurie).

- ISPRA, starting from the initial international Emercon emergency notification, activated its Nuclear Emergency Centre in order to follow the evolution of the event being a relevant national contact point in the framework of the EC and IAEA international nuclear emergency communication systems. The Centre operated giving technical support to the National Department of Civil Protection, evaluating the information received on the accident evolution with regard to the plant status, radioactive releases, environmental and food contamination. The Institute was much involved in the public information activities by issuing a daily bulletin for about a month, on the situation on the Fukushima site and in the Japanese prefectures affected by the accident, and by accommodating the media requests. The Institute coordinated the environmental monitoring activities of the national network of laboratories for the surveillance of the environmental radioactivity, belonging to Regional Environmental Agencies which detected the presence of very low level of radioactivity that could be due to the released material from the Fukushima plants.

The above mentioned activities summarizes the Italian national response to Fukushima accident. The Fukushima experience highlighted the need to develop a specific plan for situations following nuclear or radiological accident occurring very far from national boundaries. This will be taken into account in the next updating of the National Emergency Plan. It has to be said that the Fukushima accident confirmed the level of conservatism embodied in the technical bases of the emergency plan in place.

\subsection{Assessment of compliance}

Based on information reported above it may be concluded that Italy meets the requirements of this Article of the Convention. 
Article 17. Siting

Each Contracting Party shall take the appropriate steps to ensure that appropriate procedures are established and implemented:

i. for evaluating all relevant site-related factors likely to affect the safety of a nuclear installation for its projected lifetime;

ii. for evaluating the likely safety impact of a proposed nuclear installation on individuals, society and the environment;

iii. for re-evaluating as necessary all relevant factors referred to in sub-paragraphs (i) and (ii) so as to ensure the continued safety acceptability of the nuclear installation;

iv. for consulting Contracting Parties in the vicinity of a proposed nuclear installation, insofar as they are likely to be affected by that installation and, upon request providing the necessary information to such Contracting Parties, in order to enable them to evaluate and make their own assessment of the likely safety impact on their own territory of the nuclear installation.

Due to the status of the Italian NPPs, which are in a shutdown condition since many years, the requirements set out in the Convention are not directly applicable. It has however to be mentioned that that existing legal provisions (namely Law 1860 of 1962 and the Legislative Decree $n^{\circ} 230$ of 1995), provide the adequate basis to comply with the requirements established in this Article of the Convention. 
Article 18. Design and construction

Each Contracting Party shall take the appropriate steps to ensure that:

i. the design and construction of a nuclear installation provides for several reliable levels and methods of protection (defence in depth) against the release of radioactive materials, with a view to preventing the occurrence of accidents and to mitigating their radiological consequences should they occur;

ii. the technologies incorporated in the design and construction of

a nuclear installation are proven by experience or qualified by testing or analysis;

iii. the design of a nuclear installation allows for reliable, stable and easily manageable operation, with specific consideration of human factors and the man-machine interface.

Due to the status of the Italian NPPs, which are in a shutdown condition since many years, the requirements set out in the Convention are not directly applicable. It has however to be mentioned that that existing legal provisions (namely Law 1860 of 1962 and the Legislative Decree $\mathrm{n}^{\circ} 230$ of 1995), provide the adequate basis to comply with the requirements established in this Article of the Convention. 
Article 19. Operation

Each Contracting Party shall take the appropriate steps to ensure that:

i. the initial authorization to operate a nuclear installation is based upon an appropriate safety analysis and a commissioning programme demonstrating that the installation, as constructed, is consistent with design and safety requirements;

ii. operational limits and conditions derived from the safety analysis, tests and operational experience are defined and revised as necessary for identifying safe boundaries for operation;

iii. operation, maintenance, inspection and testing of a nuclear installation are conducted in accordance with approved procedures;

iv. procedures are established for responding to anticipated operational occurrences and to accidents;

v. necessary engineering and technical support in all safetyrelated fields is available throughout the lifetime of a nuclear installation;

vi. incidents significant to safety are reported in a timely manner by the holder of the relevant licence to the regulatory body;

vii. programmes to collect and analyse operating experience are established, the results obtained and the conclusions drawn are acted upon and that existing mechanisms are used to share important experience with international bodies and with other operating organizations and regulatory bodies;

viii. the generation of radioactive waste resulting from the operation of a nuclear installation is kept to the minimum practicable for the process concerned, both in activity and in volume, and any necessary treatment and storage of spent fuel and waste directly related to the operation and on the same site as that of the nuclear installation take into consideration conditioning and disposal.

Due to the status of the Italian NPPs, which are in a shutdown condition since many years, the requirements set out in the Convention are not directly applicable. It has however to be mentioned that that existing legal provisions (namely Law 1860 of 1962 and the Legislative 
Section C. Compliance with articles 4 to 19

Decree $\mathrm{n}^{\circ} 230$ of 1995), provide the adequate basis to comply with the requirements established in this Article of the Convention. 
Section D. Topics of interest from the $5^{\text {th }}$ review meeting 

1. To overcome the experienced human resources shortage in medium and long term both at the licensees and the regulator

Institutional uncertainties associated to the establishment and subsequent cancellation of the new Nuclear Safety Agency have not made possible to define and implement a comprehensive plan to strengthen the human resources at the regulatory body.

It is expected that with the assignment of functions and duties of the Nuclear safety agency to ISPRA and in the context of reorganization of the regulatory function anticipated in Law 214/2011 proper actions will be taken to overcome the referred difficulties. From the Implementer side, also affected by the issue of retirement of qualified personnel, a programme of recruitment of new personnel which need to be consolidated in the near future has been initiated.

\section{Implement procedures for siting and construction of national waste repository for disposal of low level waste and long term storage of high level waste}

The already quoted Legislative Decree n. 31/2010, mainly in art. 27, defines the procedures for locating and constructing the national repository, associated with a technological park (SF\&TP). The different steps to be accomplished in order to realize a national facility for disposal and long term interim storage of radioactive waste are described below.

The siting and licensing procedure defined in the Legislative Decree n. 31/2010 and subsequent modifications have been already summarized in the introductory section.

In can be here emphasized that, following the suppression of the new Nuclear Safety Agency in July 2012, ISPRA has been tasked by the Government to define technical criteria for the siting of the national repository. ISPRA, taking into account pertaining IAEA safety standards and technical exchanges with authorities of other countries having realized or already operating similar facilities has developed a draft technical guide on technical criteria for the siting of low level wastes disposal facility. Subsequently, this draft guide has been submitted to a peer review process by IAEA. The review process was completed in September. Technical exchange also took place with Nuclear Safety Authorities of France, Switzerland, Belgium and Slovenia. The technical guide will be now issued according to the procedure established in the Legislative Decree n. 230/1995. The issue of the criteria will allow the Implementer to start the siting procedure with the definition of a Chart of potentially suitable sites. 

Section E. Planned activities to improve safety 

Transition of the regulatory functions from ISPRA to the new Nuclear Safety Agency

As already said in other sections of the report the new Nuclear Safety Agency has been cancelled and the regulatory functions maintained to ISPRA.

\section{Start dismantling activities following granting of decommissioning license}

As already said decommissioning licence has been granted for Garigliano and Trino NPPs, respectively in August and in September 2012. For Caorso NPP a licence for a first decommissioning phase had been granted in 2000 and the overall decommissioning licence is expected by the end of the current year. For Latina NPPs it is expected in 2014.

As said, the decommissioning licence regulates the development of different activities according to specific decommissioning projects to be approved by ISPRA.

For Trino NPP priority is now assigned to the transfer of the spent fuel to France for reprocessing. A review of the operability of involved systems is in progress.

As preliminary activity the refurbishment of the containment building in order to ensure the system operability requested during decommissioning operations has been completed.

Specific decommissioning projects have been filed for the refurbishment of existing radioactive waste storage facilities and radwaste system. A specific project has been filed for the dismantling operations of the primary system.

The regulatory review of a specific system for the treatment of the primary system decontamination resins is in progress.

For the Garigliano NPP some activities are already in progress (treatment of radioactive wastes with presence of asbestos, refurbishment of parts of the plant electric system, preparatory activities for the dismantling of the chimney). A specific project has been filed for the refurbishment of the radwaste treatment system.

As said in this Report, for Caorso NPP the overall decommissioning licensing procedure has been completed and the related authorisation is expected to be granted by the end of the year. In the meantime some activities, concerning waste treatment and dismantling, have been completed (f.e. off-gas system building).

On the basis of licensing procedures conducted according to Law n.27/2012, specific authorisations have been granted for dismantling of some components of the primary systems as well as for the removal of components from the spent fuel and for its decontamination. 


\section{Treatment and conditioning of existing waste and construction of on-site storage facilities}

Several activities are in progress and planned in the NPPs to treat, condition and store radioactive waste.

Construction of two interim radioactive waste storage facilities in Garigliano NPP and one facility in Latina NPP has been completed. For one of the facilities of the Garigliano NPP also the commissioning phase has been completed. For Latina NPP the construction of a facility for treatment and conditioning of sludges derived from past operation is in an advanced stage.

Refurbishment of existing storage facilities is envisaged in the case of Trino and Caorso NPPs.

Activities for the construction of an on-site system for resins treatment at Trino NPP are under regulatory review. A treatment strategy and process will be proposed for Caorso NPP.

For Caorso NPP, a RW incineration campaign in Sweden has been completed.

For Garigliano NPP, treatment of RW with presence of asbestos is in progress.

\section{Updating of technical guides - in line with the WENRA harmonization action plan}

Three Technical guides are under preparation related to Storage of radioactive waste, Decommissioning operations and Criteria and Methodology for Release of Materials. They reflect the experience gained in the licensing activities already performed and take into account WENRA reference levels. These guide are expected to be issued for consultation as stated in the legislation in the near future.

\section{Siting and construction of national waste repository}

As already said in previous sections ISPRA has developed a Technical Guide on siting criteria for a near surface low level RW disposal facility. The elaboration process of the guide has been supported by a technical exchange of experiences with Regulatory Bodies of other EU countries which already have these facilities or have a licensing process already started and by an international review of IAEA. The Guide is going to be issued according to the procedure established in the legislation.

Continue to promote implementation of most recent concepts of safety management by licensees

As reported under paragraph 6.1, on 2009 a new Management System Manual adopted by SOGIN, the Implementer of the national decommissioning activities, was certified to be in 
compliance with the ISO 9001:2008 norms. Because of the requirements fixed by such a certification, the Safety Management System of the national Implementer can be considered as evolving to adhere to an integrated management system model complying with the IAEA GS-R3 requirements. 

Section F. List of acronyms 

AFR

ALARA

ANPA

APAT

BWR

CEI

CEVaD

CIPE

DISP

ENEA

ENEL

GCR

IAEA

ICRP

ISPESL

ISPRA

LWR

NEA

OECD

PUN

PWR

QA

SOGIN

TC

TMI

TS

UNI

WENRA
Away From Reactor

As Low As Reasonably Achievable

National Environmental Protection Agency

National Agency for the Environment Protection and Technical Services

Boiling Water Reactor

Comitato Elettrotecnico Italiano

Centre for Data Elaboration and Evaluation

Inter-Ministerial Committee for Economic Planning

Nuclear Safety and Health Protection Directorate

Agency for New Technologies, Energy and Environment

National Electricity Company

Gas Cooled Reactor

International Atomic Energy Agency

International Commission on Radiological Protection

National Prevention and Workers Safety Institute

National Institute for Environmental Protection and Research

Light Water Reactor

Nuclear Energy Agency of OECD

Organisation for Economic Co-operation and Development

Italian Nuclear Unified Project

Pressurised Water Reactor

Quality Assurance

Nuclear Installations Management Company

Technical Commission for Nuclear Safety and Health Protection

Three Mile Island NPP

Technical Specification

Ente Nazionale Italiano di Unificazione

Western European Nuclear Regulators Association 

Section G. Annexes 



\section{Annex 1 - List and status of nuclear installations in Italy}

The main general data of the four Italian nuclear installations are reported in the following table.

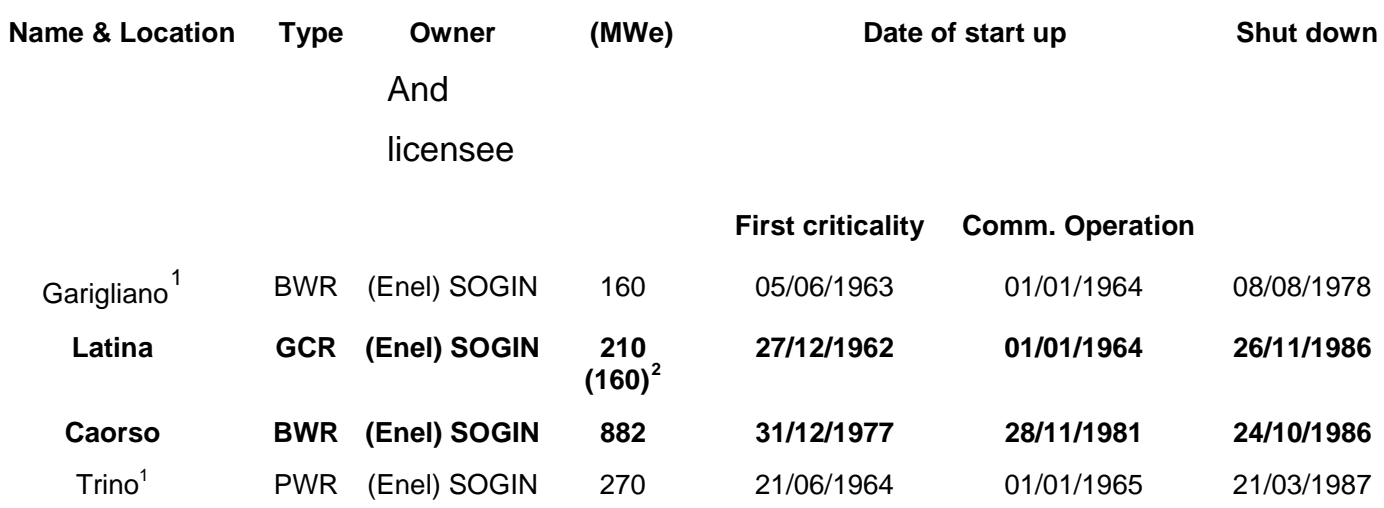

\section{A.1.1 Garigliano NPP}

The Garigliano NPP is located in a curve on the left side of the homonymous river, making the border between the regions of Campania and Lazio, about $7 \mathrm{~km}$ from the Thyrrenian Sea, in the territory of Sessa Aurunca (CE). The plant construction ended in 1963, the commercial operation took place from 1964 to 1978 and, presently, the plant is under decommissioning.

The Garigliano NPP has been designed as a dual cycle BWR plant, 506 MWt, 160 Mwe. The main nuclear components are the reactor vessel, the steam drum separator, the associated risers and downcomers tubing, two U-tubes steam generators. The nuclear island is enclosed in a steel spherical containment, $22 \mathrm{~mm}$ thick, with penetrations for connecting water-steam pipes to the turbine building.

In 1978, since structural problems had been discovered in the steam generators and given the short residual life of the plant, the owner (ENEL) took the decision to definitely shutdown the plant. In this regard the Ministry of Industry, now Ministry of Economic Development, issued in 1985 a license for the plant decommissioning based on a safe storage strategy.

In 1985-1987, the nuclear fuel (about $300.000 \mathrm{TBq}$ ) was moved from the plant, to the independent Avogadro pool in Saluggia (VC), for long term wet storage. Furthermore, extensive radwaste management activities related to low level solid technological contaminated radwaste were accomplished through treatment processes based on compaction and supercompaction, the high activity level liquid process radwaste (from the reactor water chemical cycle) through conditioning by cementation, and activated solid wastes through cementation. The generated wastes have been stored in the turbine building and in other structures on the plant site.

\footnotetext{
${ }^{1}$ Even if no longer considered as nuclear installations, information regarding Garigliano and Trino NPPs is reported for seek of completeness

2 the power was reduced with respect to the design value
} 
Another important activity was aimed to reach the safe storage condition of the reactor building (the so called CPP - "Custodia Protettiva Passiva"): extensive decontamination of accessible areas and equipment was performed, many systems and equipment were disconnected or deenergized, the nuclear components and process systems were emptied of operating fluids, their openings and penetrations were closed, fire loads in the containment were minimized, an internal sealed zone including the containment rooms with nuclear components, served with a passive filtered ventilation, was established in the containment to maintain the confinement of the residual radioactivity and to avoid its diffusion outside.

In 2001, on the basis of the Government decision to change the decommissioning strategy from safe storage to a single step decommissioning of all nuclear installations in Italy, an overall decommissioning plan was issued for Garigliano NPP. Later on, other projects have been issued and in particular, a project to build a new 4-modules structure for the temporary storage of existing wastes (about $500 \mathrm{TBq}$ ) and the future wastes from the single step decommissioning (about $700 \mathrm{TBq}$ ).

The Garigliano NPP is currently operated by SOGIN under the above mentioned safe storage licence, issued in 1985, and the associated Technical Specifications issued by the Regulatory Body (ENEA/DISP, now ISPRA). Plant operation is performed based on Surveillance Rules, Technical and Management Procedures of the Operation Manual, under a quality system regime.

Several preparatory decommissioning activities have been performed in the past years. In September 2012 the overall decommissioning licence has been granted to Garigliano NPP based on the immediate dismantling, single step strategy.

In the past years the following activities have been conducted in the site:

- $\quad$ new access to controlled area

- removal of asbestos from the containment;

- $\quad$ refurbishment of the pre-existing diesel generator building in a structure for interim storage of radioactive waste;

- $\quad$ realization of the "D1" new 1-module structure for interim storage of radioactive waste (as a modification of the 4-modules project previously mentioned),

- Implementation has to begin for the following approved projects:

- demolition of the stack and erection of a new temporary one;

- remediation of underground trenches used for storage of very low level technological radwaste (this project was approved in 2002 but was suspended waiting fora suitable radwaste storage structure).

- The following projects are still under regulatory assessment:

- $\quad$ improvement of the turbine ventilation; 
- construction of a new radwaste system to manage the future decommissioning operations waste;

- $\quad$ demolition of the piezometric tower and realization of a new water supply system;

Other relevant activities made in regard of plant decommissioning or maintaining the plant safety include: updating of the plant SAR, fire prevention and protection programme, updating of plant operation and management documentation, improvement or replacement or restoration of obsolescent equipment (i.e. fire lines and pumps, liquid radwaste discharge line, change of onsite electrical power sources).

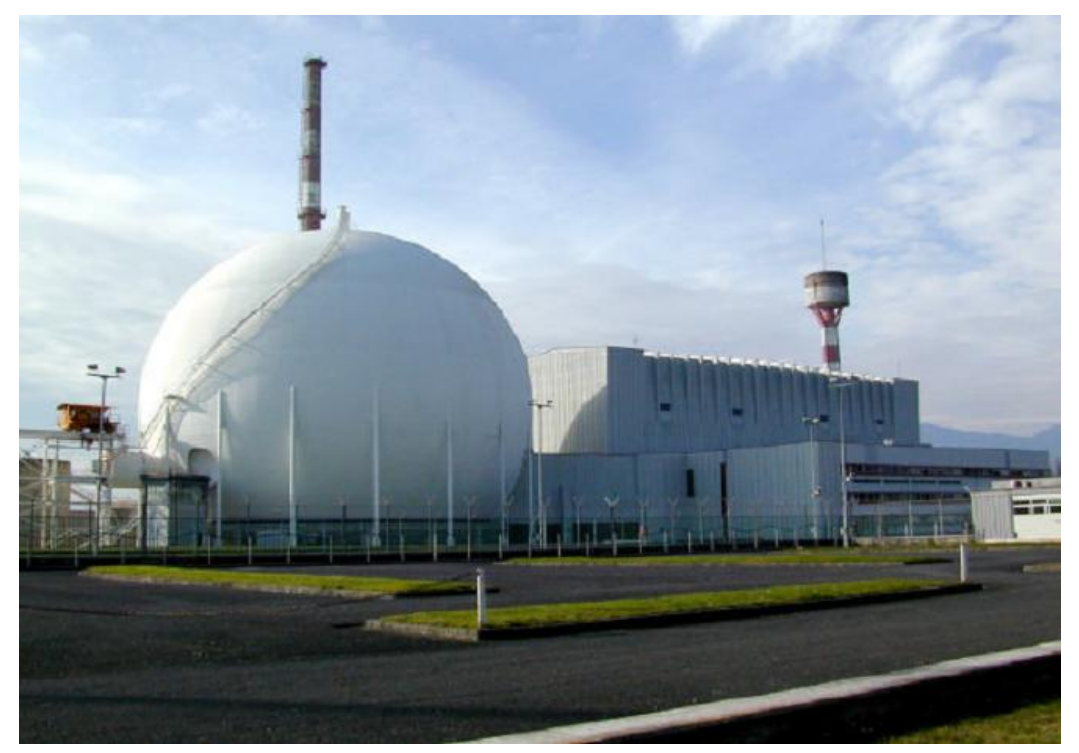

\section{A.1.2 Trino NPP}

The "Enrico Fermi" NPP, a 270 MWe PWR plant supplied by Westinghouse, is located in the northern Italy, in the territory of Trino Vercellese (VC), on the left bank of the PO river. It was operated by Enel from 1965 to 1987. Its operation was smooth, with the exception of two prolonged interruptions for implementation of important safety upgrades. After final shutdown, imposed by the Government after the Chernobyl accident, the decision was taken to put the plant in the safe storage condition (also named CPP - custodia protettiva passiva) in view of future decommissioning. In 1992 the reactor was defuelled. All fresh fuel and most of irradiated fuel was successively removed from the plant. A limited amount of spent fuel is still present in the spent fuel pool of the plant waiting to be shipped to reprocessing.

The spent fuel pool is a steel lined concrete structure $(14,7 \times 10,3 \times 11 \mathrm{~m})$. Spent fuel racks are located inside with space for 162 fuel assemblies and 150 control rods or other in core components.

At present, in the pool, there are 47 spent fuel assemblies (8 MOX and $39 \mathrm{UO} 2$ ).

In the Trino NPP there were significant activities for CPP involving mainly conventional parts, and to put out of service systems not any more required for safety. 


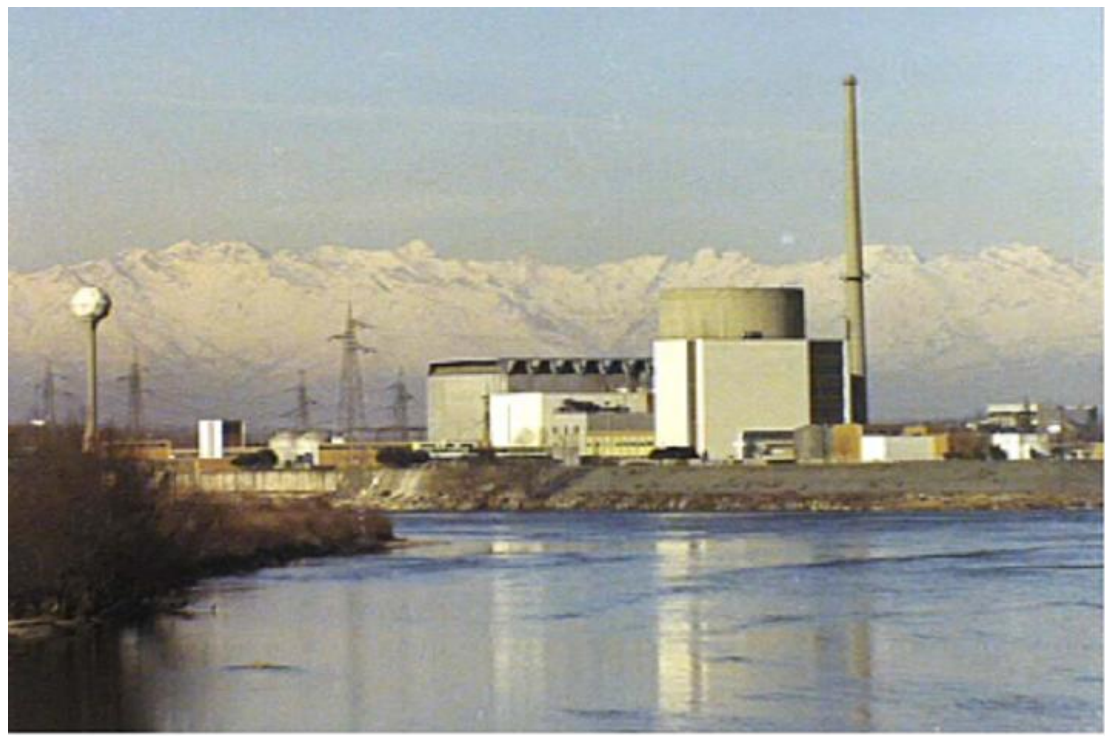

Following the change of the decommissioning strategy (December 1999), a comprehensive plan for a single step decommissioning of Trino has been submitted in 2001 for license by SOGIN (new plant Implementer in place of ENEL). The decommissioning licence has been granted in August 2012

Up to now several activities connected to decommissioning have been performed: removal of conventional parts, removal of asbestos, radwaste characterization and treatment, decontamination of steam generators, implementation of a new water supply system for the plant not derived from the Po river, modification of containment ventilation system; removal of material and equipment, located inside the controlled zone of the plant, that have been free released.

Other activities relevant to plant decommissioning or to maintaining the plant safety include: updating of the plant SAR, fire prevention and protection programme, updating of plant operation and management documentation.

At present the radioactive waste (about $1050 \mathrm{~m}^{3}, 330 \mathrm{~m}^{3}$ of which is still to be conditioned) is stored in the two storage facilities of the NPP site. Some semi-liquid radioactive waste (resins and sludges) have still to be conditioned.

In August 2012 the overall decommissioning licence has been granted to Trino NPP based on the immediate dismantling, single step strategy.

On the basis of a strategic review of the decommissioning programmes, SOGIN has recently assigned priority to the decommissioning of Trino NPP. Studies for the dismantlement of the primary circuit are underway 


\section{A.1.3 Caorso NPP}

The Caorso power station, a BWR unit (882 MWe), started its commercial operation in the year 1981 and was permanently shut down in 1986 , just after the $4^{\text {th }}$ refuelling.

Since 1998, the reactor core has been completely defuelled and all the irradiated fuel elements have been transferred to the spent fuel pools, in view of its shipping to reprocessing.

The NPP is actually regulated by a preliminary decommissioning license granted on August 4, 2000 allowing a set of preliminary activities.

The licensing procedure for the authorization of the overall plan for a single step decommissioning is close to be completed (expected in 2013).

Preliminary activities for the decommissioning carried/permitted by the license above, were as follow:

- decontamination of the circulation loops and of the clean up system has been completed on february 2004;

- dismantling activities of RHR towers were competed in 2009 while the dismantling in turbine building and off-gas system respectively ended in 2009 and 2013.

- in May 2010, ISPRA granted the permission to put into operation the Phadec plant for the chemicals decontamination of metallic materials, deriving from the dismantling inside the turbine and Off-Gas buildings;

- in June 2010 the activities for removal and transport of all the spent fuel that were started in December 2007 for a total of 1032 spent fuel elements were completed.

- the over reduction of volumes of about 600 drums of technological radioactive wastes with $1.2 \mathrm{GBq}$ of total radioactivity;

- on the bases of an international contract signed from SOGIN with Sweden company (Studvick) for the supply of treatment and conditioning services for operational radioactive wastes, in the period between July 2011 and May 2012, was carried out sending 355 ton of low activity wastes $(1.84 \mathrm{GBq})$ of Caorso NNP to be incinerated and put up in the cement matrix. In August 2013 wastes treated and conditioned returned to the site.

- At present the radioactive waste (about $2490 \mathrm{m3}, 2065 \mathrm{~m} 3$ of which is still to be conditioned) is stored in the three storage facilities of the NPP site. $1250 \mathrm{~m} 3$ of operational radioactive waste (resins and sludge) have been treated in the past with ureaformaldehyde but, due to the presence of significant amount of free (corrosive) liquids and due to a compressive strength significantly lower than the required limit of $5 \mathrm{MPa}$, a new conditioning campaign has to be performed, on request by the Regulatory Body.

\section{A.1.4 Latina NPP}

The 160 MWe GCR of Latina is located on the Tirrenian sea coast, around $70 \mathrm{Km}$ south of Rome. It was operated by Enel since 1962 until 1986. The initial installed electrical power of 210 
MWe was later downrated to $160 \mathrm{MWe}$, after a reduction of $30^{\circ} \mathrm{C}$ of coolant temperature to avoid oxidation of reactor internals. The plant was definitely shutdown in November 1986, after the Chernobyl accident, by Government decision.

Since then, all spent fuel has been removed from the plant and the primary circuit has been filled with dry air. At present, the radioactive waste derived from plant operation (about $1220 \mathrm{~m}^{3}$, $900 \mathrm{~m}^{3}$ of which is still to be conditioned) is stored in different facilities of the NPP site.

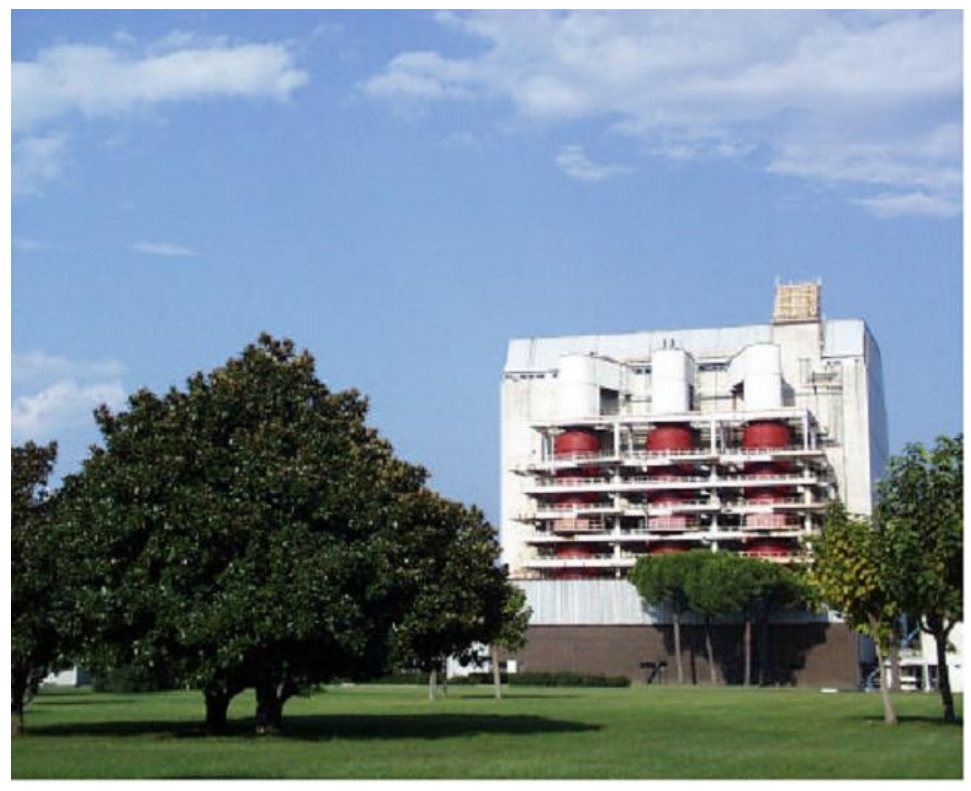

About decommissioning strategy, the initial safe storage strategy has recently switched to two phases decommissioning. The first phase foresees the putting in conservation of reactor building and the filling of the new temporary repository.

The second phase, to be implemented only after the siting and construction of the national repository, foresees the dismantling of all plant structures with the purpose to reach the green field end state.

The plant is currently operated under a license issued in 1991 that establishes the procedures for the operability of safety relevant systems, radwaste management, public and workers radiological protection and environmental monitoring.

An overall plan for the decommissioning of Latina was submitted by SOGIN under a new application and is currently under review by ISPRA. The licensing procedure is expected to be completed in 2013.

Some dismantling activities have already been licensed and performed, while other activities are currently being carried out as summarized below: 
- $\quad$ structures and parts of the plant considered no longer safety related such as fuel charge/discharge machines, $\mathrm{CO} 2$ production and storage system and auxiliary piping have been disassembled and removed;

- all fuel elements (22441 for a weight of $256 \mathrm{t}$ ) have been removed and sent to BNFL for reprocessing;

- the fuel pond is partially decontaminated through a scrabbling process (only the emergency and decay sections of the pond);

- $\quad$ about the charge section of the pond, SOGIN has submitted to ISPRA a new request for the decontamination of this section;

- $\quad \mathrm{CO}_{2}$ auxiliary piping has been removed;

- $\quad$ water and steam piping has been removed;

- all 6 gas circulators have been removed (cases still on site as part of primary containment);

- the circulators halls were released from structures and components;

- $\quad$ thermal insulation has been removed from gas conduits and steam generators;

- $\quad$ the primary circuit has been dismantled;

- a project for the extraction and conditioning of sludges (licensed in 2003) actually is in realization phases; in particular for what concerns the construction of the buildings of extractions and conditioning;

- $\quad$ the construction of a new interim storage facility has been completed and commissioning tests are close to come.

The following activities have recently been approved and are being done the planning stages:

- removal of large components from fuel pond and its decontamination;

- removal and decontamination of shells blower;

- construction of a station for the treatment of materials derived from dismantling of the LT NNP.

In 2013, the demolition of the turbine building was completed

Licensing procedures for the following projects are also in progress:

- extraction and conditioning of Magnox residues;

removal of system components of reactor building; construction of a new Liquid radwaste treatment facility.

About $20.000 \mathrm{~m} 3$ of radioactive wastes are expected from decommissioning activities, among which around $2000 \mathrm{t}$ of graphite: such wastes cannot be stored of on the site, not even temporarily, so that the availability of a national facility for the radwaste storage is critical for the completion of the decommissioning activities. 
Section G. Annexes 


\section{Annex 2 - Background historical information on the past Italian nuclear programme}

Commercial utilisation of nuclear power in Italy started in 1964 and within 1981 four nuclear power plants, namely the NPPs of Garigliano (BWR), Latina (Gas Grafite), Trino (PWR) and Caorso (BWR), and a LEU fuel fabrication installation (Fabbricazioni Nucleari S.p.A.) had been commissioned.

During that period, an extensive R\&D programme on the nuclear fuel cycle was developed by the Nuclear Energy Research Agency (CNEN) - now the National Agency for New Technology, Energy and the Environment (Enea) - with the operation of experimental fuel cycle installations (e.g. ITREC and EUREX).

The three NPPs of Latina, Trino and Caorso continued to be operated until 1987, when they were definively shut down based on a governmental decision which in such a way interpreted the results of a national referendum called upon after the Chernobyl accident. The NPP of Garigliano had been already shut down in 1978, for technical reasons.

At the same time, the nuclear programme was closed, the Interministerial Committee for the Economical Planning (CIPE) required the National Electricity Company (Enel S.p.A.) to start the decommissioning of the NPPs and a "safe storage" (IAEA level 1/2) option was adopted.

In 1999, all Enel S.p.A. liabilities and assets connected to nuclear power were assigned to a newly established company, named SOGIN (Società Gestione Impianti Nucleari) S.p.A., whose shareholder is the Ministry of Economy and Finance, while the strategic and operational aims are given by the Ministry of Productive Activities, now of Economic Development. The primary mission of the SOGIN S.p.A. is to cover the decommissioning of all Italian nuclear installations and the safe management of the spent fuel and radioactive waste.

The spent fuel and the largest part of the radioactive waste to be managed in Italy derive from the operation of the above mentioned NPPs and fuel cycle facilities. As far as spent fuel is concerned, part of that has already been transferred abroad for reprocessing (namely the fuel of Latina and part of the fuel of Garigliano and Trino NPPs). In the framework of the InterGovernmental reprocessing agreement referred in the policy section (2006-07) the transfer abroad of the remaining amount of fuel still in Italy is close to be completed. According to said agreement, the treated and conditioned waste resulting from the reprocessing will be returned to Italy.

The technical guidance and standards that at the early 60ties were initially assumed as reference for the design, construction and operation of NPPs were essentially the ones developed in the Country where the specific technology was originated. The reasons for that are easily understandable if one thinks that NPPs had a US and UK origin. 
A long process of assimilation into the main stream of the industrial and regulatory practices has been taking place since the inception of the Italian nuclear program. The results of that assimilation process developed into an indigenous conception of the safety and radiation protection criteria. In this context it must be remarked that radiation protection concepts such as justification and optimisation were long in use even before the formal introduction into the legislative corpus of rules. Moreover, in the 80ties, some specific Italian requirements were introduced into a new homogeneous corpus establishing general criteria and requirements applicable to pressurised light water reactors. That process lead to an approach that resulted in establishing integration between safety and radiation protection requirements. Full use of probabilistic assessments was required by applicants for demonstration of having met the radioprotection objectives in terms of doses to members of the public for the entire spectrum of operational scenarios (including transients and accidents).

A reflection of the adoption of nuclear US technologies has been the use of some parts of 10 CFR (U.S. Code of Federal Regulations), and of other US industrial standards. 


\section{Annex 3 - List of acts, decrees, regulations, guides and standards}

a) Statutes and Legislative acts

Act no. 1860 of 31 December 1962: published in the Italian Republic's Official Journal no. 27 of 30 January 1963, as amended by the President's Decree no. 1704 of 30 December 1965 (Italian Republic's Official Journal no. 112 of 9 May 1966) and by the President's Decree no. 519 of 10 May 1975 (Italian Republic's Official Journal no. 294 of 6 November 1975);

Presidential Decree no. 185 of 1964: "Safety of plants and protection of workers and general public against the risk of ionising radiation associated to the peaceful use of Nuclear Energy replaced in 1996 by the Legislative Decree no. 230/1995, described below;

Act no. 393/1975: which contains Administrative rules on the selection of the site for NPPs;

Presidential Decree no. 1450/1971: which contains Requirements and procedure for the acquisition of the operational personnel licences;

Presidential Decree no. 519/1975: "Civil responsibilities in the field of nuclear safety";

Legislative Decree no. 230 of 17 March 1995: published in the Supplement to Italian Republic's Official Journal no. 136 of 13 June 1995, which has been in force in Italy since January 1st 1996 - and replaces the Presidential Decree no. 185/1964, the previous radiation protection act -, implements six EURATOM Directives on radiation protection (EURATOM 80/836, 84/467, 84/466, 89/618, 90/641 and 92/3). Legislative Decree no. 230 needs a series of Government and Ministerial Decrees;

Legislative Decree no. 241 of 26th May 2000: which has transposed EU (European Union) directive 96/29/Euratom laying down basic safety standards for the radiation protection of workers and the public; the standards laid down in the directive incorporate the 1990 Recommendations of the International Commission on Radiation Protection (ICRP) into EU radiation protection legislation. Decree no. 241 has modified and integrated Legislative Decree no. 230 of 1995, the latter constitutes the main piece of legislation laying down radiation protection requirements for workers and the public;

Legislative Decree no. 257 of 9th May 2001: which modified certain details in Legislative Decree no. 241 of 2000 concerning requirements for notification and authorisation of non nuclear installations where ionising radiation is used for industrial, research and medical purposes;

Decree of $2^{\text {nd }}$ December 2004 of the Ministry of Productive Activities (now Economic Development) provides directives to SOGIN for the implementation of decommissioning and radioactive waste management activities. The Decree also charges SOGIN to explore the feasibility of sending all the spent fuel currently stored in ITALY to abroad for reprocessing. 
Legislative Decree $n .52$ of $6^{\text {th }}$ February 2007 which transposes EU directive 2003/122/Euratom on the control of high-activity sealed radioactive sources and orphan sources.

Legislative Decree no. 23 of 20th February 2009: which has transposed EU directive 2006/117/Euratom on the supervision and control of shipments of radioactive waste and spent fuel; Legislative Decree no. 23/2009 has modified pertinent administrative provisions previously contained in Legislative Decree no. 230/1995 concerning the transboundary shipments of radioactive waste. Legislative Decree no. 230/1995 now contains new provisions on the supervision and control of shipments of spent fuel.

Law $n^{\circ}$ 99/2009, related to the process to start a new nuclear programme, in Article 29, establishes a new Nuclear Safety Agency with the role of Regulatory Body. As already mentioned, the Agency will be made by the resources of the Nuclear Department of ISPRA and by resources from the Agency for New technologies, Energy and sustainable development (ENEA). The full establishment of this new Safety Authority has, however, still to be completed.

Legislative Decree $n^{\circ} \mathbf{3 1 / 2 0 1 0}$ related to the future nuclear development in Italy, provides criteria for the site selection procedure with the involvement of local administration, for the approval and for the compensation of the local municipality. The Decree includes also provisions for the site selection procedure of the national site for radioactive waste disposal giving the responsibility to SOGIN.

On the consequences of the Fukushima accident, the recent Referendum held on 12 June 2011 definitely sanctioned the abandon of the nuclear power development programme in Italy started in 2009.

Legislative Decree $n^{\circ}$ 41/2011 amended the Legislative Decree 31/2010 with reference to the future nuclear development in Italy.

Law $n^{\circ} 75$ of May $26^{\text {th }}$ 2011, That modifies all the provisions given in the Law $n^{\circ}$ 99/2009 and in the Legislative Decree $n^{\circ} 31 / 2010$, as amended by the Legislative Decree $n^{\circ} 41 / 2011$, relevant to the development of new NPP in Italy, relinquishing the nuclear development in Italy. The provisions for the development of the national site for LLW disposal and ILW-HLW interim storage has been confirmed. Furthermore, by abrogating the Articles 8 and 9 of the Legislative Decree no. 230 of 1995, The Law 75/2011 slightly modifies the regulatory process by cancelling of the "Technical Commission on Nuclear safety and Radiation Protection". This Commission was entitled to formulate an independent technical advice to ISPRA during the assessment process connected to the 
granting of licences, authorizations and approval of detailed designs.

Legislative Decree $\mathbf{n} .100$ of 1st June 2011 which modifies the provisions of article 157 of Legislative Decree $n^{\circ}$ 230/1995 concerning the radiometric surveillance of metal scraps.

Legislative Decree $n^{\circ}$ 185/2011 which transposes the EU Council Directive 2009/71/Euratom establishing a Community framework for the nuclear safety of nuclear installations.

Law $n^{\circ} 214$ of December 2011 abolished the Nuclear Safety Agency (created with the Law 99/2009, but not yet applied) and the functions have been temporary assigned to ISPRA (that in fact continue its work as nuclear authority) waiting for a definitive asset of the regulatory organization.

Law $n^{\circ} 27$ of March 2012 on the economic development, through the Art. 24, establishes new procedures to reduce the timing of the licensing phases for decommissioning activities with a strong involvement of local administrations.

Act no. 933/1960: on the establishment of the National Committee for Nuclear Energy (CNEN);

Act no. 84/1982: on the establishment of the State Agency for new technologies, energy and environment (ENEA);

Act no. 61/1994: on the establishment of the National Agency for the Environment Protection (ANPA);

Legislative Decree $n^{\circ}$ 300/1999 and President of the Republic Decree $n^{\circ}$ 207/2002: on the establishment of APAT, by merging ANPA with other national Technical Services;

Act no. 286/2006: on the reorganisation of APAT as a legal entity of public administration, endowed with new institutional Organs;

Law $n^{\circ} 368$ of $24^{\text {th }}$ December 2003: establishing the procedures for the site selection of a national repository for HLW;

Law $n^{\circ} 239$ of $23^{\text {rd }}$ August 2004: promulgated for the rearrangement of the energy sector extends the procedures established by the Law $n^{\circ} 368$ of 2003 also for the site selection of a national repository of LLW;

Law $n^{\circ} 10$ of $19^{\text {th }}$ January 1998: promulgated for the ratification of the Convention on Nuclear Safety;

Law $n^{\circ} 282$ of $16^{\text {th }}$ December 2005: promulgated for the ratification of Joint Convention on the Safety of Spent Fuel Management and on the Safety of Radioactive Waste Management;

Law $n^{\circ} 100$ of $12^{\text {th }}$ July 2012: regarding provisions on civil protection reorganisation. 
b) Technical guides - Selected APAT TG addressed to Nuclear Installations' licensing

Doc. DISP (87) 10 "General Design Criteria for PWR NPPs";

Doc. DISP (87) 11 "Design Requirements for the limitation of the worker exposure for the PWR NPPs";

T.G. no.1

"Content of the Preliminary Safety Analysis Report for NPPs, pursuant to article no.36 of the Legislative Decree no. 2301995 “;

T.G. no.2

"Procedure for the Authorisation of Changes in NPPs";

T.G. no.4 "Implementation of the article no.41 of the Legislative Decree no.230/1995 --Detailed Construction Designs“;

T.G. no.8

"Quality Assurance Criteria for NPPs";

T.G. no.9

"Quality Assurance Description of the documentation required for design and construction phases prior to carry out nuclear tests";

T.G. no.11

"Criteria for the compilation of information reports on the operation of NPPs to be sent to DISP“;

T.G. no.20

"Quality Assurance Description of the documentation required for operation phase of NPPs";

T.G. no.21

"Content of Operating Rules";

T.G. no.22

"Quality Assurance. Guide for collection, storage, preservation, and safekeeping of quality assurance records for NPPs";

T.G. no.23 "Quality Assurance. Guide for procurement of Items and Services for NPPs“;

T.G. no.24 "Quality Assurance. Guide for Auditing on QA Programmes for NPPs“;

T. G. no.25 "Quality Assurance. Guide for Applying on design activities for NPPs";

T. G. no.26

"Radioactive Waste Management;

T.G. no.27

"In-service Inspection".

c) Technical Standards

$\underline{\text { UNI standards related to decommissioning }}$

The Standards applicable to the decommissioning of Italian installations are set out in a single document issued by the national standards organisation (UNI): UNI 9498. 
That standard contains eight sections covering different topics. The contents of the individual sections of the document are summarised below.

In general the present standard pertains explicitly to the following type of installations:

- nuclear reactors:

- nuclear subcritical units;

- nuclear power plants;

- $\quad$ nuclear research plants;

- $\quad$ nuclear plants for spent fuel reprocessing;

- $\quad$ plants for preparation and fabrication of special fissile materials and of nuclear fuel;

- $\quad$ storage of special fissile materials and of nuclear fuel;

- installations for reprocessing, conditioning or temporary storage of radioactive wastes.

The standard is not applicable to:

- $\quad$ uranium mines:

- $\quad$ storage of final disposal of radioactive wastes;

- $\quad$ plant where during the operation, no radioactivity has been produced;

- $\quad$ plants which have been converted to a new nuclear related use.

\section{$\underline{\text { UNI 9498/1 - General criteria }}$}

This standard gives a general picture that includes principles and factors which have to be considered for the decommissioning of a nuclear plant. It includes the general requirement that all the procedures, either of a management, accounting and administrative type, or of a technical type, must be planned and done in a controlled and documented way.

The standard is addressed to the operator of nuclear plants to be decommissioned and to persons responsible for the planning and execution of decommissioning operations; it provides to indications and recommendations about the methods and the technical options which are convenient in order to maintain an adequate health protection for workers, public and environment, and finally to minimise the radiological risk associated to the plant.

The scope of the standard begins at the decision of the owner/operator to permanently shut down the plant, and terminates when a situation without radiological constraints is reached. The status of the plant taken as a reference in the present standard is the configuration existing at the moment the decision is made to permanently shut down. The radioactive substances considered are those associated with the normal operation of the plant itself. The standard does not deal with decommissioning activities following a severe accidents. 
The aspects related to processing, conditioning, transportation and disposal of radioactive wastes are not included in the scope of the standard. The numerical definition of radioactivity limits for materials free from radiological constraints are also not included. Nor the management, accounting and administrative aspects. The standard does not exempt the user from observing the rules and authorising procedures in force.

\section{$\underline{\text { UNI 9498/2 - Decontamination techniques }}$}

The section describes the principles and the methodologies which have to be considered for the planning and execution of decontamination activities at a nuclear plant being decommissioned, for the case of either immediate or deferred dismantling. It provides technical information and recommendations necessary to the owner/operator of the plant and to people responsible for the planning and execution of all the decontamination procedures which are useful in improving the conditions of radiological protection at the plant as well as in achieving the optimum management of wastes.

It is not applicable to plants which, following an accident, show a generalised contamination of components, structures and buildings and of the site itself. In this case specific decontamination techniques will be have to set up, and they are allowed to be different to those described in the present standard.

\section{UNI 9498/3 - Storage and surveillance}

This section identifies the fundamental activities which are necessary to be done on a nuclear plant at the end of operation, to leave it in a safe condition for an adequate period of time. It is concerned in particular with plants where the existing radioactivity, after the complete removal of all fissile materials, is due primarily to radioisotopes which have decay times which justify placing the plant in a conservation and maintenance (C\&M) state for appropriate period, in order to allow the plant to be completely dismantled with a greatly reduced level of radioactivity.

\section{UNI 9498/4 - Dismantling of structures and components}

This section describes the principles and the factors which have to be taken into account for the dismantling and removal of structures and components which have become contaminated and/or activated during the operation of the plant.

\section{$\underline{\text { UNI 9498/5 - Radioactive inventory }}$}

This section specifies the methodologies to be followed in the evaluation of the remaining radioactivity and of the associated radiation fields in order to carry out the radiological 
characterisation of the nuclear plants to be decommissioned. Such methodologies must be programmed and performed in a checked and documented way.

\section{UNI 9498/6 - Radiological characterisation and classification of materials}

This section deals with the factors which have to be taken into account to characterise and classify the materials produced during the decommissioning of nuclear plants. It provides the criteria against which the most appropriate methodology for characterisation and classification of materials as a function of their type is to be chosen, as well as provides guidance for the choice of measurement instrumentation appropriate to define the radiological state of the materials.

\section{UNI 9498/7 - Criteria for partial release of a nuclear plant and/or site}

This section deals with those nuclear plants to be decommissioned for which a decision has been made to delay final dismantling for a sufficiently long period of time, such that they will have to be placed in a C\&M state.

The decision of putting a part of a nuclear plant in a C\&M state depends on the requirement to release some zone where other activities of a non nuclear type can continue to be performed.

Usually the part of the plant that will be put in a C\&M state will be that part where the radioactivity cannot be easily removed but can be confined for long periods of time in well defined and sealed zones. Usually these are areas where the major part of the radioactivity is coming from neutron activation.

\section{UNI 9498/8 - Requirements for the temporary storage of radioactive wastes and materials}

This section gives the criteria to be followed in the design of a temporary store for the radioactive wastes resulting from the operation and dismantling of the nuclear plants. It also provides the general technical requirements which have to be fulfilled either in the design and management of the new temporary store, or in the modification of already existing facilities.

Furthermore it provides the criteria for environment protection against pollution resulting from management of radioactive wastes, in order to minimise the individual and collective doses of population and workers, and to preserve the quality of the environment for the present and future uses of the site. 
The radioactive wastes mentioned above include those arising from reprocessing and/or conditioning activities, that are solid and satisfy the radioactivity concentration limits according to present standards for temporary storage or for disposal at an appropriate site.

\section{$\underline{\text { UNI standards related to radioactive waste management }}$}

In the framework of the National Standardization Organisation (UNI) activities, the following standards aiming to the standardisation of the procedures for radioactive waste management have been developed:

UNI 10621 (2004) "Radioactive waste packages characterization";

UNI 10704 (2004) "Radioactive waste classification";

UNI 10755 (2004) "Recording and labelling of RW packages";

UNICEN 189 (2001) "Solid materials from nuclear plants - Radiological methods and procedures for the clearance";

UNI11193 (2006) "Qualification of conditioning processes for cat. 2 packages", that sets out the general requirements for the conditioning process qualification and the specific test to which the waste form and/or packages should be verified (mechanical and physical/chemical properties for homogeneous and heterogeneous waste form and for High Integrity Containers);

UNI 11194 (2006) "Radiological characterization of Cat.2 packages", that establishes methods and requirements for radiological characterization of radioactive waste packages before their disposal (i.e. measurement system performances, typical radionuclides relevant for disposal to be measured, sampling preparation, correlation factors);

UNI 11195 (2006) "Information management system for the disposal of Cat. 2 packages", that sets out the requirements and the methodologies for the management of the Surface Disposal Information Management System (i.e. data aquisition, waste reception plan, inspection and monitoring data base, long term management of the information system);

UNI 11196 ( 2006) "Containers for the final repository of Cat. 2 packages" That defines the requirements (dimension, mechanical characteristics) of the identified containers for LLW packages and qualification process; 
UNI 11197( 2006)

UN11197(2006)

UNICEN 214-1 (2003)
"Identification procedure and traceability of information for Cat.2 Packages", that defines the requirements for building a suitable Data Base and for organising the information needed to appropriately manage radioactive waste packages at a near surface disposal facility;

"Category 2 Radioactive Waste Engineered Repository", that is structured as follows:

- Part 1: Basic Design Criteria;

- Part 2: Basic Qualification Criteria for Engineered Barriers;

- Part 3: Surveillance and Monitoring basic criteria. 


\section{Annex 4 - Additional information on safety and radiation protection rules}

As referred in Article 15, the radiation protection in Italy is regulated by the Legislative Decree 230/1995 and its modifications.

One of the most relevant provisions in Legislative Decree no. 230/1995 is the distinction between practices and intervention, as defined in EU directive 96/29/Euratom in accordance with the Recommendations of ICRP Publication 60: the basic principles of justification and optimization (the latter being also called ALARA, i.e. requiring doses to be kept as low as reasonably achievable) apply both to practices and to intervention although the wording is somewhat different. As far as the third principle of dose limitation is concerned, in cases of intervention on the contrary such principle does not apply, intervention levels being used in its stead.

The Legislative Decree 230/1995 clearly state that the operator of a nuclear installation or non nuclear installations or facilities making use of radioactive materials, must implement all the safety and protection measures suitable to keep the exposures of workers and population as low as reasonably achievable, social and economic considerations being kept into account. The implementation of the optimization principle by the operator must be demonstrated firstly at the design stage and subsequently along the plant operation and decommissioning.

As far as situations concerning unplanned or uncontrolled releases of radioactive material into the environment are concerned, it has been a practice in the authorisation procedure - in force in Italy since 1964 - to request to the applicant an analysis of possible scenarios and the assessment of the consequences (in terms of radiological impact on critical groups of the public), together with appropriate measures implemented with a view of preventing and controlling accident conditions, and mitigating their consequences, with the aim of establishing ad hoc emergency plans. Following the transposition of the Directive 96/29/Euratom in the Legislative Decree 230/1995, an analogous provision was introduced also for non nuclear installations.

\section{A.4.1 Practices}

In accordance with the provisions of Legislative Decree no. 230/1995, a practice is subject to radiation protection requirements if certain thresholds of activity and concentration are exceeded:

- $1 \mathrm{~Bq} / \mathrm{g}$ in activity concentration for all radionuclides, and

- relevant activity values for each radionuclide from Euratom directives 84/467 and 96/29, whichever the lesser.

However, for certain practices, such as medical use of radiation, deliberately adding radioactivity to consumer goods, importing and exporting such goods, discharges, reuse or 
recycle of radioactive materials from installations, the Italian legislation's requirements apply for any radioactivity contents, without thresholds.

The concept of triviality in individual and in collective doses as well as provisions for unrestricted release of radioactive materials from installations have also been formally introduced into Italian legislation according to the following basic 'below regulatory concern' criterion, both conditions of which must be met:

a) effective dose $\leq 10 \mu$ Sv/year, and

b) either collective effective dose committed in one year of performance of the practice not greater than about 1 man.Sv or the relevant analysis demonstrates that exemption is the optimum option.

From an administrative viewpoint, practices can be subject to the mutually exclusive requirements either of notification or of authorisation. In accordance with the new provisions of Legislative Decree no. 230/1995.a practice is subject to notification requirements starting from defined thresholds in activity and activity concentration as far as radioactive materials are concerned; the relevant thresholds are those laid down in Annex I of EU directive 96/29/Euratom. A holder of sources is required to notify local authorities of his intention to carry out the practice at least 30 days before the start of the practice. Besides, detailed requirements for notification apply which closely mirror those provided for in case of authorisation.

The Legislative Decree's provisions state that a practice is subject to notification insofar as requirements for authorisation do not apply. In particular, nuclear installations do not require notification since they continue being subject to the ad hoc authorisation requirements laid down in Legislative Decree no. 230/1995, which have not been modified by the transposition of EU directive 96/29/Euratom.

For non nuclear installations using ionising radiation for medical, industrial and research purposes the Italian authorisation system is based, as in the past, on a two tiered structure: authorisation of the more important installations is the competence of the of Ministry of Economic Development which issues authorisations in accordance with other relevant Ministries; the advice of APAT is sought under law in order to determine technical specifications applicable to the installation.

For smaller industrial and research installations the Prefect of the province has administrative competence to issue authorisations after seeking the advice of regional technical bodies and of the Fire Corps; the authorisation required for small medical installations is issued by the Regions, which are responsible for health in the Italian system.

A Technical Annexe to Legislative Decree no. 230/1995 lays down thresholds in order to determine which installations are authorised by the Ministry of Economic Development and which ones by local authorities; thresholds are set in terms of values of activity, activity concentration and neutron yield for radioactive sources, and of energy and neutron yield for 
accelerators. The same Annexe also lays down the technical features of the radiation sources and of the installation which must be specified in the application.

A general criterion is in force in Italy for unrestricted release from any installation subject to either notification or authorisation requirements. Radioactive materials from such practices can be unconditionally released from regulatory control if the radionuclides concerned comply with conditions regarding both activity concentration and radioactive half life:

- activity concentration $\leq 1 \mathrm{~Bq} / \mathrm{g}$, and

- half-life $<75$ days.

If conditions above are not complied with, an authorisation is required for release, reuse and recycle of radioactive materials from the installation concerned and specifications to that effect are established in the licence. The authorisation is given on the basis of a case-by-case analysis which has to demonstrate compliance with the basic 'below regulatory concern' criterion stated above. In the case where the practice is not subject per se to authorisation requirements, as for instance in the case where notification applies, a special authorisation for release is provided for. The clearance levels to be specified in the prescriptions, must comply with the basic below regulatory concern criterion for practices - also established in the European Directive 96/29/Euratom - and, to this aim, must take into account directives, recommendations and technical positions provided by the European Union. The contravention to prescriptions included in the authorisation acts is opposed by ad hoc sanctions.

\section{A.4.2 Intervention}

As regards intervention in cases of emergency, it must be stated beforehand that requirements for detailed emergency plans providing for intervention in case of accidents in nuclear installations had been in force in Italy since Presidential Decree no. 185 of 1964 was promulgated. Further requirements to that effect have been introduced in Legislative Decree no. 230/1995 by transposing EU directive 96/29/Euratom providing for intervention in cases of radiological emergencies in non nuclear installations and for exposure resulting from the after effects of a radiological emergency or of a past or old practice or work activity, which were not regulated in previous radiation protection legislation.

As previously said, since the promulgation in 1964 of the first Radiation Protection Decree it had been a practice in the authorisation procedures to request of the applicant an analysis of possible accident scenarios and of their radiological consequences, together with appropriate measures to be implemented with a view to preventing and controlling accident conditions, and mitigating their consequences.

Given that nuclear installations proper continue to be subject to a special separate regime as in the past, ad hoc provisions introduced into Legislative Decree no. 230 of 1995 by Legislative Decree no. 241 of 2000 require for each non nuclear installation subject to authorisation by the 
Ministry of Economic Development that evaluations of potential exposures should be made by the applicant seeking an authorisation and submitted to licensing authorities so that an intervention plan can be prepared by emergency preparedness and management Authorities.

For those non nuclear installations which require authorisation by the Prefect or by the Regions, licensing authorities will review evaluations of potential exposures made by the applicant and will decide whether such potential exposures are likely to exceed $1 \mathrm{mSv}$ of effective dose; in this case an intervention plan can be prepared by emergency preparedness and management Authorities as well. No new installation can start operations before approval of an intervention plan if the former is required under the new rules.

A Technical Annex in Legislative Decree no. 230/1995, also introduced by Legislative Decree no. 241 of 2000, lays down indicative intervention levels in terms of effective, equivalent and absorbed doses for purposes of planning and intervention in case of emergency; broadly, the levels established are in accordance with the European Commission's guidelines (Radiation Protection 87 "Radiological protection principles for urgent countermeasures to protect the public in the event of accidental releases of radioactive material") and with criteria in IAEA Safety Series no. 109 ("Intervention criteria in a Nuclear or Radiological Emergency").

\section{A.4.3 Dose limits}

The transposing of the EU directive 96/29/Euratom in Legislative Decree no. 230 of 1995 has also led to establishing a new dose limit for exposed workers of $20 \mathrm{mSv}$ in a calendar year. Instead of Annual Limits on Intake (ALI), age dependent coefficients relating a unit of intake of a radionuclide to committed effective dose for workers and members of the public are now in use in accordance with the EU directive mentioned above.

\section{A) WORKERS}

The following limits shall not be exceeded for exposed workers:

- an effective dose of $20 \mathrm{mSv}$ in any single (calendar) year;

- a dose equivalent of $150 \mathrm{mSv}$ per year to the lenses of the eyes;

- a dose equivalent of $500 \mathrm{mSv}$ per year to skin, forearms, hands, feet and ankles.

However, in exceptional circumstances, recourse can be made to specially authorised exposures for medically fit category A workers (as hereinbelow defined) if exceeding dose limits cannot be avoided; such exposures can be incurred only by voluntary workers and must not exceed twice the yearly limits laid down for exposed workers. In particular, no women of reproductive capacity can undergo such exposures; the same rule applies to male workers having exceeded dose limits in the twelve months before. 
Special provisions ensure that workers having exceeded the effective dose limit of $20 \mathrm{mSv}$ for any reason whatever must not be exposed in excess of $10 \mathrm{mSv}$ per calendar year as long as their yearly averaged exposures are no more than $20 \mathrm{mSv}$.

\section{WORKER CLASSIFICATION CRITERIA}

An individual, in relation to his work activity, can be classified:

a) non-exposed worker, if he is not likely to receive, because of his work, doses exceeding the following limits in a (calendar) year:

- $\quad$ an effective dose of $1 \mathrm{mSv}$, or

- an equivalent dose of $15 \mathrm{mSv}$ to the lenses of the eye, or

- $\quad$ an equivalent dose of $50 \mathrm{mSv}$ to skin, forearms, hands, feet and ankles;

(the above limits are numerically equal to those laid down for members of the public).

b) exposed worker, if in relation to his work activity he has a likelihood to receive doses exceeding the limits indicated in a).

Exposed workers can be classified in two categories for monitoring and surveillance purposes: Category A and Category B workers.

Category A workers: Exposed workers are classified in such category when they have a likelihood to receive in a calendar year doses exceeding:

- $\quad$ an effective dose of $6 \mathrm{mSv}$, or

- $\quad$ an equivalent dose to the lenses of the eye of $45 \mathrm{mSv}$, or

- $\quad$ an equivalent dose to skin, forearms, hands, feet and ankles of $150 \mathrm{mSv}$.

Category A workers must be individually monitored, both for external and internal exposures while for category $B$ workers area monitoring is used, as a rule, in order to assess doses and to verify compliance with ALARA constraints and, of course, with dose limits.

Category B workers: occupational exposure of any worker shall be so controlled through area monitoring that the previous dose levels for purposes of classification are not exceeded.

Other special provisions are laid down in Legislative Decree no. 230 of 1995 with a view to protecting: apprentices and students of age $\geq 18$ years (who are training for employment involving exposure to radiation), the worker classification criteria shall be applied; apprentices and students of age between 16 and 18 years (who are training for employment involving exposure to radiation); apprentices and students of age 16 years or less; pregnant and nursing women. 
Moreover, delineation of work areas (i.e. supervised and controlled areas) based upon by reference to an assessment of the expected annual doses and the probability and magnitude of potential exposures, thus distinguishing work areas at risk in controlled and surveyed areas.

According to EURATOM directive no. 90/641, special provisions were established in the Legislative Decree no. 230/1995 for outside workers and in particular the use of a radiation "passport", logging doses incurred during their working activities.

B) MEMBERS OF THE PUBLIC

The following limits shall not be exceeded for members of the public:

- $\quad$ an effective dose of $1 \mathrm{mSv}$ per year;

- a equivalent dose to the lenses of the eye of $15 \mathrm{mSv}$ per year;

- a equivalent dose to skin of 50 mSv per year.

\section{A.4.4 Radiological safety objectives and Authorised Limits}

The Italian Regulatory Practice has always made intensive use of radiological safety objectives and authorised limits for ensuring that, during normal operating conditions, doses to workers and reference groups of the population are well below primary dose limits.

As regards transient and accident conditions, radiological criteria applicable to each kind of installation are identified, seeking to differentiate between various types of transient and accidental conditions in terms of maximum dose levels not to be exceeded to the relevant reference groups of the populations.

\section{A.4.5 Surveillance}

For the implementation of provisions regarding radiation protection of workers and public, the Italian regulatory system identifies a particular person, the qualified experts, whose technical qualification is recognised through State examinations. Those professionals have been playing an advisory role and bearing technical responsibility, as far as radiation protection is concerned; their role consists in carrying out both preventive and periodical radiation protection evaluations and measurements, in particular regarding dose assessments both for workers and members of the public. Moreover qualified experts bear technical responsibility in that they must give operators all technical advice relevant to ensuring effective radiation protection of workers and public at the design stage, at the operational level and at the decommissioning stage.

An important instrument for the radiation protection of exposed workers is medical surveillance carried out by specialised physicians whose capacity to act as approved medical practitioners is recognised by means of State examinations. Every member of the work force must be recognised as fit prior to being exposed to radiation as a category A or B worker and is also subject to periodic reviews of health. 
All considerations, evaluations, measurements and technical advice by qualified experts must be recorded, in particular as regards dose assessment records for which a strict regime of filing is provided for; the same requirement for filing holds for records concerning medical surveillance of exposed workers.

\section{A.4.6 Radiation Protection Inspections and enforcement}

Verification of compliance with radiation protection requirements laid down in law and in licensing prescriptions is the responsibility of various independent bodies. ISPRA inspectors are vested with authority over the whole domain of radiation protection requirements as both workers and public are concerned, Labour Inspectorates are concerned with requirements pertaining to workers' protection while Inspectors with regional bodies are mainly concerned with radiation protection requirements for the public. It must be remembered that Inspectors are vested with police powers in the Italian system.

The Italian compliance and inspection system is based upon the fact that legislation provides for penal sanctions in cases of non compliance; penalties are meted out by the Courts at the instigation of the Office of Public Prosecution to which inspectors are required under law to communicate every case of non compliance. Particular measures are laid down in legislation in order to prompt and/or force swift compliance, especially for non compliance concerning provisions for radiation protection of workers; in these cases inspectors are bound to evaluate if the user could avoid undergoing a trial by complying with ad hoc specifications established by inspectors and paying a fine.

\section{A.4.7 The ALARA Principle}

The principle that doses incurred in relevant exposures are to be kept as low as reasonably achievable, social and economic considerations being kept into account, is laid down in article 2 of Legislative Decree no. 230 of 1995, together with the principles of justification and of dose limitation. It must be remembered that the optimisation principle, together with the justification principle, had been implemented in Italian regulatory philosophy and practices long before it was legislated into the Legislative Decree no. 230/1995.

The implementation of the ALARA principle in the Italian system of regulatory control is ensured by means of two regulatory tools:

- $\quad$ provisions in the Legislative Decree no. 230/1995;

- $\quad$ administrative prescriptions.

The Legislative Decree has distinct provisions for doses to workers and public to be kept ALARA by operators: the provisions state, essentially, that rules of good practice are to be obeyed at every stage. Rules of good practice are not an exclusive means to ensure 
optimisation as ALARA is also called: other means may be used to that end provided that results are the same.

The second regulatory tool, largely employed in the Italian system for the purpose of implementing ALARA, is the use of administrative prescriptions at every stage of the licensing process. It must be pointed out that such prescriptions are enforceable by means of criminal penalties.

From an operational viewpoint the whole of the regulatory instruments available, that is:

- the careful planning at the design stage, through the laying down of the radiological safety objectives;

- the consequent safety assessment and all ensuing reviews;

- the safety and radiation protection culture fostered among all Italian organisations involved,

- $\quad$ the good independent prevention role played by qualified experts;

- $\quad$ the support role by the NPP Council of Delegates;

- $\quad$ the system for verification of compliance.

all have conspired so that a more than satisfactory radiation protection level from the ALARA viewpoint was ensured for all stages of the installation life.

\section{A.4.8 Incident reporting}

The most important provisions are contained in Legislative Decree no. 230/1995, namely Articles 92 and 100.

In case of accidents, or incidents that could result in an exposure to workers above dose limits, according to article 92 of the Legislative Decree no. 230/1995, the operator is requested for notification as soon as possible, but not later than 3 days after, to the following Institutions:

The Regulatory Body (ISPRA);

Local Labour Inspectorate (Province);

Local Offices of the National Health Services.

In case of unexpected radioactive contamination inside the plant boundaries or an accidental occurrence implying a significant increase of the risk of exposure to the workers, the Operator has to implement all suitable measures aiming at avoiding any risk increase (article 100 of the Legislative Decree no. 230/1995). Moreover, when significant contamination of air, water or land outside the plant boundary, or exposure to the public, at the occurrence of accidental events, the operator is required to immediately notify to:

- Local Government Representative (Prefect);

- Local Fire Brigade; 
- Local Offices of the National Health Services;

- The Regulatory Body (ISPRA).

Furthermore, the operator has to take all the measures suitable to reduce the radioactive contamination in the areas outside the boundary of the plant, so to limit the risk to the public. 


\section{Annex 5 - Structure of the global decommissioning programme}

According to the reference legislative provisions, the overall decommissioning programme that SOGIN has submitted for each NPP, covers the operations lasting from the preliminary activities until the site release and is structured in three main stages as hereinafter summarized.

\section{First stage:}

a) interventions, partly already in progress, aimed at improving safety conditions, such as:

- $\quad$ enhancing physical protection;

- $\quad$ removing spent fuel from nuclear island;

- $\quad$ treating and conditioning of radioactive waste generated during past operation;

- $\quad$ removing structures and material implying conventional risks (e.g. asbestos, unsafe structures).

b) design and implementation of activities which can facilitate subsequent decommissioning operations, such as:

- dismantling parts of the plants not contaminated or with low contamination;

- $\quad$ construction of temporary storage repositories;

- $\quad$ installation of new ventilation systems;

- $\quad$ refurbishment of safety systems revealing ageing problems.

Second stage: dismantlement of the nuclear island, decontamination of buildings, completion of waste treatment;

Third stage: completion of buildings' demolition, performing a final radiological survey and site release. 


\section{Author Team (in alphabetical order)}

Luciano BOLOGNA - ISPRA, Nuclear Department

Mario DIONISI - ISPRA, Nuclear Department

Giuseppe Mariano CASCIO - ISPRA, Nuclear Department

Lamberto MATTEOCCI - ISPRA, Nuclear Department

Roberto RANIERI - ISPRA, Nuclear Department

Paolo ZEPPA - ISPRA, Nuclear Department

Contributions by SOGIN and by other contributors whom we express our thanks for their cooperation. 
